\title{
Do Banking Shocks Matter for the U.S. Economy?
}

\author{
Naohisa Hirakata*, Nao Sudo ${ }^{\dagger}$ and Kozo Ueda
}

January 20, 2010

\begin{abstract}
There is ample empirical evidence suggesting that adverse shocks to the financial intermediary (FI) sector cause large economic downturns. The quantitative significance of these shocks to the U.S. business cycle, however, has not been studied much so far. To evaluate the importance of these shocks, we estimate the stickyprice dynamic stochastic general equilibrium (DSGE) model that incorporates the credit market imperfection associated with FIs. In this model, financial intermediaries (FIs), along with entrepreneurs, are credit constrained, and shocks to their net worth cause aggregate fluctuations through the financial accelerator mechanism. Using Bayesian estimation, we extract the shocks to the FIs' net worth. We find these effects to be persistent, lowering economic activity for several quarters after the recessionary trough. According to variance decomposition, the shocks to the FI sector account for at least $10 \%$ of investment variation, but have a relatively minor influence on the variations in output and inflation. During the financial crisis starting in 2007, shocks account for $24 \%$ of the decline in investment, $10 \%$ of the decline in output and $20 \%$ of the decline in inflation.
\end{abstract}

Keywords: Monetary Policy; Financial Accelerators; Financial Intermediaries.

${ }^{*}$ Deputy Director, Research and Statistics Department, Bank of Japan (E-mail: naohisa.hirakata@boj.or.jp)

${ }^{\dagger}$ Associate Director, Institute for Monetary and Economic Studies, Bank of Japan (E-mail: nao.sudou@boj.or.jp).

${ }^{\ddagger}$ Director, Institute for Monetary and Economic Studies, Bank of Japan (E-mail: kouzou.ueda@boj.or.jp). The authors would like to thank Klaus Adam, Jinill Kim, Hiroshi Osano, Toshiaki Watanabe, Wako Watanabe, Tack Yun, seminar participants at Kyoto University, the Bank of Canada, the Bank of Italy and the staff of the Institute for Monetary and Economic Studies (IMES) and the Bank of Japan for their useful comments. The authors particularly thank Simon Gilchrist and Lawrence Christiano for their encouragement at the outset of this research. The views expressed in this paper are those of the authors and do not necessarily reflect the official views of the Bank of Japan. 


\section{Introduction}

The financial crisis starting in the fall of 2007 demonstrated that financial intermediaries (hereafter, FIs) play a critical role in economic activity. Adverse shocks to the financial intermediary (FI) sector increase the borrowing costs for FIs through deterioration of their net worth, resulting in a widening of spreads in the credit market. Consequently, the supply of funds to entrepreneurs tightens, leading to an investment decline and a further deterioration of the FIs' balance sheets. This account is consistent with the literature that focuses on the relationship between the FI sector and the aggregate economy (e.g., Peek and Rosengren, 1997, 2000; Calomiris and Mason, 2003; Anari, Kolari and Mason, 2005; Ashcraft, 2005). For example, Peek and Rosengren (1997, 2000), using a novel identification scheme for a loan supply shock, report that the worsening of FIs' credit conditions generates macroeconomic downturns.

However, it remains unknown how important the shocks to the FI sector are to the U.S. business cycle. While it is widely agreed among macroeconomists that shocks to the credit market are an important source of aggregate fluctuations (Christiano, Motto and Rostagno, hereafter CMR, 2003, 2007, 2008; Gilchrist, Yankov and Zakrajsek, 2009; Jermann and Quardini, 2009), to our best knowledge only a limited number of studies have evaluated the relative impact of shocks in the FI sector. ${ }^{1}$ In the existing models, shocks to entrepreneurial net worth are primarily studied and shocks to the FIs' net worth are often neglected.

To assess the role of the shocks to FIs, we estimate the financial accelerator model of Hirakata, Sudo and Ueda (2009a, 2009b, hereafter HSU). This model is built upon the framework in Bernanke, Gertler and Gilchrist (1999, hereafter BGG). In the model, there are two credit-constrained borrowers, FIs and entrepreneurs, and two credit spreads, the FIs' loan spread (the differential between the FIs' loan rate and the FIs' borrowing rate) and the FIs' borrowing spread (the differential between the FIs' borrowing rate and the riskless rate). The two spreads are related to the net worth of borrowers by the costly state verification type of credit contracts. Similarly to BGG, the financial accelerator effect is active in this model. However, in contrast to BGG, the effect originates from two sources. That is, shocks to the economy are amplified and propagated through the endogenous development of net worth in the two sectors. Because there are now two net worths compared with the BGG model, the financial accelerator effect is reinforced (HSU, 2009a).

Based on HSU, we have distilled the shocks to the FIs' net worth using a Bayesian technique. We make use of a set of U.S. macroeconomic variables consisting of output,

\footnotetext{
${ }^{1}$ The notable exceptions are CMR $(2007,2008)$, where shocks to the production functions of banks are analyzed separately from the shocks to entrepreneurs. While other empirical work, such as Peek and Rosengren (1997, 2000), emphasize the balance sheet effect in the FI sector, the banks in CMR are competitive and do not own their net worth. In contrast, we focus on the shocks to FIs' net worth and their impact on the aggregate economy through the deterioration of credit conditions.
} 
consumption, investment, inflation, the policy rate and the net worth-capital ratio of both the FI and the entrepreneurial sector. ${ }^{2}$ The sample period runs from 1984Q1 to 2009Q2, and therefore covers the most recent turmoil in the credit market. We find that our estimated FI shocks are negatively correlated with various indicators of credit market stress, suggesting the importance of net worth in the FI sector during the financial crisis.

Based on the decomposition of the historical contributions of structural shocks, we also find that the adverse shocks to the FI sector are an important, but not the dominant, source of economic fluctuations in the United States. Their impacts on investment and output last long, lowering them for several quarters after the end of the recession. To prices, these shocks bring deflationary pressure throughout the period. We find the relative contributions of these shocks to investment, output and inflation variations, respectively, to be $13 \%, 10 \%$ and $5 \%$ for the entire sample period, and $20 \%, 8 \%$ and $5 \%$ for the period after 1990. During the recession starting in 2007, more particularly, shocks to FIs contribute $24 \%, 10 \%$ and $20 \%$ of the declines in investment, output and inflation, respectively.

Research using the financial accelerator model (CMR; Meier and Muller, 2006; Christensen and Dib, 2008; De Graeve, 2008; Nolan and Thoenissen, 2009) commonly poses either or both of two questions. The first is about the quantitative importance of the financial accelerator mechanism, and the second concerns the quantitative importance of shocks to the credit market. For instance, Christensen and Dib (2008), in response to the first question, conclude that the financial accelerator effect brings the sticky-price dynamic stochastic general equilibrium (DSGE) model closer to the data. However, they also point out that its quantitative contribution is small. ${ }^{3}$ From a different perspective, Nolan and Thoenissen (2009), in response to the second question, report that shocks to the credit market account for $45 \%$ of the variations in output and investment.

Our model provides an alternative view. First, by comparing fit with the data, we find that our model, in which both FIs and entrepreneurs are credit constrained, outperforms the model in which only the entrepreneurs are credit constrained. We also find the latter model outperforms the model that abstracts from the credit market imperfection at all. This exercise suggests that the financial accelerator mechanisms, especially those coming from the FI sector, are crucial elements in explaining data. Second, similarly to the existing literatures, our result implies that shocks to the credit market matters to the macroeconomy. However, we find that the most of the estimated shocks to the credit market are in fact originating from the FI sector, rather than the entrepreneurial sector

The remainder of the paper is organized as follows. In Section 2, we describe our economy. In Section 3, we describe the estimation method and the results. Section 4 concludes.

\footnotetext{
${ }^{2}$ As discussed below, we conduct several sensitivity analyses of the choice of observable variables.

${ }^{3}$ Meier and Muller (2006) derive a similar conclusion that the financial accelerator effect is small by investigating impulse response functions to monetary policy shocks using U.S. data.
} 


\section{The Economy}

We consider an economy with a credit market and a goods market. The economy consists of 10 types of agents: a household, investors, FIs, entrepreneurs, capital goods producers, final goods producers, retail goods producers, wholesale goods producers, the monetary authority and the government.

The setting for the credit market is taken from HSU (2009a). There are three types of participants in the credit market: investors, FIs and entrepreneurs. Investors collect deposits from the household in a competitive market, and invest what they collect in loans to the FIs. FIs are the monopolistic lenders of funds to entrepreneurs. FIs own their net worth, but not sufficiently to finance their loans to the entrepreneurs. Therefore, they make credit contracts with investors to borrow the rest of the funds. Entrepreneurs conduct investment in their projects. They also own their net worth, but not sufficiently to finance their projects. Thus, they create credit contracts with FIs to borrow. Clearly, these two types of contracts are linked in the economy, and entrepreneurs cannot finance their projects if either of the credit contracts fails to hold.

Monopolistic FIs determine the borrowing rates of the credit contracts, thereby ensuring the participation constraints of entrepreneurs and investors. There agency problems arising from the asymmetric information between lenders and borrowers for both of the credit contracts, one between FIs and entrepreneurs (hereafter, FE contracts) and the other between investors and FIs (hereafter, IF contracts). ${ }^{4}$ Consequently, the borrowing rates of the credit contracts change with the net worth of the borrowers.

We closely follow BGG for the setup of the goods market. There are four goods in the economy: final goods, retail goods, wholesale goods and capital goods. Final goods are produced by final goods producers from differentiated retail goods through the DixitStiglitz aggregator. Retail goods are produced by monopolistic retail goods producers who set the prices of their goods à la Calvo (1983) from wholesale goods. Wholesale goods are produced by competitive wholesalers that own a Cobb-Douglas production technology that converts capital and labor inputs into wholesale goods. Capital is produced by capital producers and sold to the entrepreneurs. In what follows, we briefly describe our setting of the credit market and fully explain the goods market.

\footnotetext{
${ }^{4}$ Our setting thus contrasts with other banking models based on the moral hazard problems of FIs and entrepreneurs (Chen, 2001; Meh and Moran, 2004; Aikman and Paustian, 2006). These studies all develop quantitative extensions of the model in Holmstrom and Tirole (1997) and illustrate the role of net worth in the banking sector. Importantly, in their model a rise in net worth mitigates the moral hazard problem, and affects aggregate investment by changing the incentive compatibility conditions. Our model, on the other hand, stresses the role of net worth in affecting the borrowing rates of the credit contracts. Consequently, the theoretical relationship for the net worth of FIs and entrepreneurs and their borrowing rates is explicitly given.
} 


\subsection{Credit Market}

\section{Overview of the credit contract}

In this section, we describe the framework of the credit contracts. In each period, entrepreneurs conduct projects with size $Q\left(s^{t}\right) K\left(s^{t}\right)$, where $Q\left(s^{t}\right)$ is the price of capital and $K\left(s^{t}\right)$ is capital. Entrepreneurs own the net worth, $N^{E}\left(s^{t}\right)<Q\left(s^{t}\right) K\left(s^{t}\right)$, and borrow funds, $Q\left(s^{t}\right) K\left(s^{t}\right)-N^{E}\left(s^{t}\right)$, from the FIs through the FE contracts. The FIs also own net worth, $N^{F}\left(s^{t}\right)<Q\left(s^{t}\right) K\left(s^{t}\right)-N^{E}\left(s^{t}\right)$, and borrow funds, $Q\left(s^{t}\right) K\left(s^{t}\right)-N^{F}\left(s^{t}\right)-N^{E}\left(s^{t}\right)$, from investors through the IF contracts. In both contracts, agency problems stemming from asymmetric information are present. That is, the borrowers are subject to idiosyncratic productivity shocks and the lenders cannot observe without paying additional costs. ${ }^{5}$ Taking these credit market imperfections as given, the FIs choose the clauses of the two contracts that maximize their expected profits. Consequently, for a given riskless rate of the economy $R\left(s^{t}\right)$, the external finance premium $\mathrm{E}_{t} R^{E}\left(s^{t+1}\right) / R\left(s^{t}\right)$ is expressed by:

$$
\begin{aligned}
& \text { inverse of share of profit going to the investors in the IF contract } \\
& \frac{\mathrm{E}_{t}\left\{R^{E}\left(s^{t+1}\right)\right\}}{R\left(s^{t}\right)}=\overbrace{\Phi^{F}\left(\bar{\omega}_{t}^{F}\left(\frac{N^{F}\left(s^{t}\right)}{Q\left(s^{t}\right) K\left(s^{t}\right)}, \frac{N^{E}\left(s^{t}\right)}{Q\left(s^{t}\right) K\left(s^{t}\right)}\right)\right)^{-1}} \\
& \text { inverse of the share of profit going to the FIs in the FE contract } \\
& \times \overbrace{\Phi^{E}\left(\bar{\omega}_{t}^{E}\left(\frac{N^{E}\left(s^{t}\right)}{Q\left(s^{t}\right) K\left(s^{t}\right)}\right)\right)^{-1}} \\
& \text { ratio of the debt to the size of the capital investment } \\
& \times \overbrace{\left(1-\frac{N^{F}\left(s^{t}\right)}{Q\left(s^{t}\right) K\left(s^{t}\right)}-\frac{N^{E}\left(s^{t}\right)}{Q\left(s^{t}\right) K\left(s^{t}\right)}\right)} \\
& \equiv F\left(n^{F}\left(s^{t}\right), n^{E}\left(s^{t}\right)\right) \text {, }
\end{aligned}
$$

with:

\footnotetext{
${ }^{5}$ The standard deviations of the idiosyncratic productivity shocks for FIs and entrepreneurs are denoted by $\sigma^{F}$ and $\sigma^{E}$. In Section 3, we investigate how our results change when these standard deviations are time-variant.
} 


$$
\begin{aligned}
& \Phi^{F}\left(\bar{\omega}^{F}\left(s^{t+1} \mid s^{t}\right)\right) \equiv \Gamma^{F}\left(\bar{\omega}^{F}\left(s^{t+1} \mid s^{t}\right)\right)-\mu^{F} G^{F}\left(\bar{\omega}^{F}\left(s^{t+1} \mid s^{t}\right)\right) \\
& \Phi^{E}\left(\bar{\omega}^{E}\left(s^{t+1} \mid s^{t}\right)\right) \equiv \Gamma^{E}\left(\bar{\omega}^{E}\left(s^{t+1} \mid s^{t}\right)\right)-\mu^{E} G^{E}\left(\bar{\omega}^{E}\left(s^{t+1} \mid s^{t}\right)\right) \\
& \text { expected productivity of defaulted FIs } \\
& \Gamma^{F}\left(\bar{\omega}_{i}^{F}\left(s^{t+1} \mid s^{t}\right)\right) \equiv \overbrace{G^{F}\left(\bar{\omega}_{i}^{F}\left(s^{t+1} \mid s^{t}\right)\right)} \\
& +\bar{\omega}_{i}^{F}\left(s^{t+1} \mid s^{t}\right) \overbrace{\int_{\bar{\omega}_{i}^{F}\left(s^{t+1} \mid s^{t}\right)}^{\infty} d F^{F}\left(\omega^{F}\right)}^{\text {portion of non-defaulted FIs }}, \\
& \Gamma^{E}\left(\bar{\omega}_{j_{i}}^{E}\left(s^{t+1} \mid s^{t}\right)\right) \equiv \overbrace{G^{E}\left(\bar{\omega}_{j_{i}}^{E}\left(s^{t+1} \mid s^{t}\right)\right)}^{\text {expected productivity of defaulted entrepreneurs }} \\
& +\bar{\omega}_{j_{i}}^{E}\left(s^{t+1} \mid s^{t}\right) \overbrace{\int_{\bar{\omega}_{j_{i}}^{E}\left(s^{t+1} \mid s^{t}\right)}^{\infty} d F^{E}\left(\omega^{E}\right)}^{\text {portion of non-defaulted entrepreneurs }},
\end{aligned}
$$

where $n_{t}^{F}\left(s^{t}\right)$ and $n_{t}^{E}\left(s^{t}\right)$ are the ratios of net worth to aggregate capital in the two sectors. ${ }^{6}$ Equation (1) is a key equation that links the net worth of the borrowing sectors to the external finance premium. The external finance premium is determined by three components: the share of profit in the IF contract going to the investors, the share of profit in the FE contract going to the FIs and the ratio of total debt to aggregate capital. Lower profit shares going to the lenders bring about a higher external finance premium through the first two terms of equation (1). Otherwise, the participation constraints of investors would not be met and financial intermediation fails. A higher ratio of the debt results in higher external costs, since it raises default probability of the IF contracts and investors require higher returns from the IF contracts to satisfy their participation constraint. It is important to note that the presence of the first two channels suggests that not only the sum of both net worths, but also each of the two net worths, matter in determining external finance premium. Net worth in the FI sector (the entrepreneurial sector) primarily helps reducing the external finance cost in the IF contract (FE contract). Because the two net worths are not substitutable, however, the external finance premium is also affected by the distribution of net worth across each sector.

\section{Borrowing rates}

The two credit borrowing rates, namely, the FIs' lending rate and the FIs' borrowing rate, are given by the $\mathrm{FE}$ and the IF contracts, respectively. These variables correspond to those observed in the financial market, namely, interest rates of interbank market

\footnotetext{
${ }^{6}$ Similarly to BGG and CMR, the aggregation problem of the FIs and the entrepreneurs becomes tractable thanks to the property of optimal credit contracts where the ratio of net worth to capital is the same within FIs and within entrepreneurs.
} 
and interest rates of entrepreneurs' borrowing market. The FI's lending rate, denoted by $Z^{E}\left(s^{t+1} \mid s^{t}\right)$, is given as the contractual interest rate that nondefaulting entrepreneurs repay to the FIs:

$$
\begin{aligned}
Z^{E}\left(s^{t+1} \mid s^{t}\right) & \equiv \frac{\bar{\omega}^{E}\left(s^{t+1} \mid s^{t}\right) R^{E}\left(s^{t+1} \mid s^{t}\right) Q\left(s^{t}\right) K\left(s^{t}\right)}{Q\left(s^{t}\right) K\left(s^{t}\right)-N^{E}\left(s^{t}\right)} \\
& =\frac{\bar{\omega}^{E}\left(s^{t+1} \mid s^{t}\right) R^{E}\left(s^{t+1} \mid s^{t}\right)}{1-n^{E}\left(s^{t}\right)}
\end{aligned}
$$

where $\bar{\omega}^{E}\left(s^{t+1} \mid s^{t}\right)$ is the cutoff value for the entrepreneurial idiosyncratic shock $\omega^{E}\left(s^{t+1}\right)$ specified in the FE contract. Clearly, the numerator stands for the amount that the nondefaulting entrepreneurs repay to the FIs, and the denominator for the amount of funds that entrepreneurs borrow from the FIs.

Similarly, the FI's borrowing rate, denoted by $Z_{i}^{F}\left(s^{t+1} \mid s^{t}\right)$, is given by the contractual interest rate that non-defaulting FIs repay to the investors. That is:

$$
\begin{aligned}
Z^{F}\left(s^{t+1} \mid s^{t}\right) & \equiv \frac{\bar{\omega}^{F}\left(s^{t+1} \mid s^{t}\right) \overbrace{\left[\Gamma^{E}\left(\bar{\omega}^{E}\left(s^{t+1} \mid s^{t}\right)\right)-\mu^{E} G^{E}\left(\bar{\omega}^{E}\left(s^{t+1} \mid s^{t}\right)\right)\right]}^{\text {share of entrepreneurial earnings received by FI }} R^{E}\left(s^{t+1} \mid s^{t}\right) Q\left(s^{t}\right) K\left(s^{t}\right)}{Q\left(s^{t}\right) K\left(s^{t}\right)-N^{F}\left(s^{t}\right)-N^{E}\left(s^{t}\right)} \\
& =\frac{\bar{\omega}^{F}\left(s^{t+1} \mid s^{t}\right)\left[\Gamma^{E}\left(\bar{\omega}^{E}\left(s^{t+1} \mid s^{t}\right)\right)-\mu^{E} G^{E}\left(\bar{\omega}^{E}\left(s^{t+1} \mid s^{t}\right)\right)\right] R^{E}\left(s^{t+1} \mid s^{t}\right)}{1-n^{F}\left(s^{t}\right)-n^{E}\left(s^{t}\right)}
\end{aligned}
$$

where $\bar{\omega}^{F}\left(s^{t+1} \mid s^{t}\right)$ is the cutoff value for the FI's idiosyncratic shock $\omega^{F}\left(s^{t+1}\right)$, specified in the IF contract. $\Gamma^{E}\left(\bar{\omega}^{E}\left(s^{t+1} \mid s^{t}\right)\right)$ and $\mu^{E} G^{E}\left(\bar{\omega}^{E}\left(s^{t+1} \mid s^{t}\right)\right)$ represent the gross expected share of profit going to the lenders and the expected monitoring costs that the lenders pay in the FE contract, respectively. In equation (3), the numerator is the amount that the nondefaulting FIs repay to the investors, and the denominator is the amount of funds that the FIs borrow from the investors.

\section{Dynamic behavior of net worth}

The net worth of FIs and entrepreneurs, $N^{F}\left(s^{t}\right)$ and $N^{E}\left(s^{t}\right)$, depends on their earnings from the credit contracts and their labor income. In addition to the profits stemming from entrepreneurial projects, both FIs and entrepreneurs inelastically supply a unit of labor to final goods producers and receive labor income $W^{F}\left(s^{t}\right)$ and $W^{E}\left(s^{t}\right)$. As we assume that each FI and entrepreneur survives to the next period with a constant probability $\gamma^{F}$ and $\gamma^{E}$, then the aggregate net worths of FIs and entrepreneurs are given by:

$$
\begin{aligned}
& N^{F}\left(s^{t+1}\right)=\gamma^{F} V^{F}\left(s^{t}\right)+W^{F}\left(s^{t}\right), \\
& N^{E}\left(s^{t+1}\right)=\gamma^{E} V^{E}\left(s^{t}\right)+W^{E}\left(s^{t}\right),
\end{aligned}
$$

with: 


$$
\begin{aligned}
V^{F}\left(s^{t}\right) \equiv & \left(1-\Gamma^{F}\left(\bar{\omega}^{F}\left(s^{t+1}\right)\right)\right)\left(\Gamma^{E}\left(\bar{\omega}^{E}\left(s^{t+1}\right)\right)-\mu^{E} G^{E}\left(\bar{\omega}^{E}\left(s^{t+1}\right)\right)\right) \\
& \times R^{E}\left(s^{t+1}\right) Q\left(s^{t}\right) K\left(s^{t}\right), \\
V^{E}\left(s^{t}\right) \equiv & \left(1-\Gamma^{E}\left(\bar{\omega}^{E}\left(s^{t+1}\right)\right)\right) R^{E}\left(s^{t+1}\right) Q\left(s^{t}\right) K\left(s^{t}\right) .
\end{aligned}
$$

FIs and entrepreneurs that fail to survive at period $t$ consume $\left(1-\gamma^{F}\right) V^{F}\left(s^{t}\right)$ and $\left(1-\gamma^{E}\right) V^{E}\left(s^{t}\right)$, respectively.

\subsection{The Rest of the Economy}

\section{Household}

A representative household is infinitely lived, and maximizes the following utility function subject to the budget constraint:

$$
\max _{C\left(s^{t}\right), H\left(s^{t}\right), D\left(s^{t}\right)} \sum_{l=0} \exp \left(e^{B}\left(s^{t+l}\right)\right) \beta^{t+l} \mathrm{E}_{t}\left\{\log C\left(s^{t+l}\right)-\chi \frac{H\left(s^{t+l}\right)^{1+\frac{1}{\eta}}}{1+\frac{1}{\eta}}\right\},
$$

subject to:

$$
C\left(s^{t}\right)+D\left(s^{t}\right) \leq W\left(s^{t}\right) H\left(s^{t}\right)+R\left(s^{t}\right) D\left(s^{t-1}\right)+\Pi\left(s^{t}\right)-T\left(s^{t}\right),
$$

where $C\left(s^{t}\right)$ is final goods consumption, $H\left(s^{t}\right)$ is hours worked, $D\left(s^{t}\right)$ is real deposits held by investors, $W\left(s^{t}\right)$ is the real wage measured by the final goods, $R\left(s^{t}\right)$ is the real risk-free return from the deposit $D\left(s^{t}\right)$ between time $t$ and $t+1$ and $T\left(s^{t}\right)$ is a lump-sum transfer. $\beta \in(0,1), \eta$ and $\chi$ are the subjective discount factor, the elasticity of leisure and the utility weight on leisure, respectively. $e^{B}\left(s^{t}\right)$ is a preference shock with mean one that provides the stochastic variation in the discount factor.

\section{Final goods producer}

The final goods $Y\left(s^{t}\right)$ are composites of a continuum of retail goods $Y\left(h, s^{t}\right)$. The final goods producer purchases retail goods in the competitive market, and sells the output to a household and capital producers at price $P\left(s^{t}\right) . P\left(s^{t}\right)$ is the aggregate price of the final goods. The production technology of the final goods is given by:

$$
Y\left(s^{t}\right)=\left[\int_{0}^{1} Y\left(h, s^{t}\right)^{\frac{\epsilon\left(s^{t}\right)-1}{\epsilon\left(s^{t}\right)}} d h\right]^{\frac{\epsilon\left(s^{t}\right)}{\epsilon\left(s^{t}\right)-1}},
$$

where $\epsilon\left(s^{t}\right)>1$. The corresponding price index is given by:

$$
P\left(s^{t}\right)=\left[\int_{0}^{1} P\left(h, s^{t}\right)^{1-\epsilon\left(s^{t}\right)} d h\right]^{\frac{1}{1-\epsilon\left(s^{t}\right)}} .
$$


$\epsilon\left(s^{t}\right)$ fluctuates, responding to the price markup disturbance $e^{P}\left(s^{t}\right)$. That is:

$$
\log \left(\epsilon\left(s^{t}\right)-\epsilon\right)=e^{P}\left(s^{t}\right)
$$

\section{Retailers}

The retailers $h \in[0,1]$ are populated over a unit interval, each producing differentiated retail goods $Y\left(h, s^{t}\right)$, with production technology:

$$
Y\left(h, s^{t}\right)=y\left(h, s^{t}\right),
$$

where $y_{t}\left(h, s^{t}\right)$ for $h \in[0,1]$ are the wholesale goods used for producing the retail goods $Y_{t}\left(h, s^{t}\right)$ by retailer $h \in[0,1]$. The retailers are price takers in the input market and choose their inputs taking the input price $1 / X\left(s^{t}\right)$ as given. However, they are monopolistic suppliers in their output market, and set their prices so as to maximize profits. Consequently, the retailer $h$ faces a downward sloping demand curve:

$$
Y\left(h, s^{t}\right)=\left(\frac{P\left(h, s^{t}\right)}{P\left(s^{t}\right)}\right)^{-\epsilon\left(s^{t}\right)} Y\left(s^{t}\right) .
$$

Retailers are subject to nominal rigidity. They are able to change prices in a given period only with probability $(1-\xi)$, following Calvo (1983). Retailers who cannot reoptimize their price in period $t$, say $h=\bar{h}$, set their prices according to:

$$
P\left(\bar{h}, s^{t}\right)=\left[\pi\left(s^{t-1}\right)^{\gamma_{p}} \pi^{1-\gamma_{p}}\right] P\left(\bar{h}, s^{t-1}\right),
$$

where $\pi\left(s^{t-1}\right)$ denotes the gross rate of inflation in period $t-1$, i.e., $\pi\left(s^{t-1}\right)=P\left(s^{t-1}\right) / P\left(s^{t-2}\right)$. $\pi$ denotes a steady state inflation rate, and $\gamma_{p} \in[0,1]$ is a parameter that governs the size of price indexation. Denoting the price set by the active retailers by $P^{*}\left(h, s^{t}\right)$ and the demand curve the active retailer faces in period $t+l$ by $Y^{*}\left(h, s^{t+l}\right)$, retailer $h$ 's optimization problem with respect to its product price $P^{*}\left(h, s^{t}\right)$ is written in the following way:

$$
\begin{aligned}
& \sum_{l=0}^{\infty} \xi E_{t} \Lambda\left(s^{t+l}\right)\left(\frac{\pi^{\left(1-\gamma_{p}\right) l}\left(\prod_{k=0}^{l-1} \pi^{\gamma_{p}}\left(s^{t+k}\right)\right) P^{*}\left(h, s^{t}\right) Y\left(h, s^{t+l}\right)}{P\left(s^{t+l}\right)}\right. \\
& \left.-\frac{\left(\frac{P\left(s^{t+l}\right)}{X\left(s^{t+l}\right)}\right) Y\left(h, s^{t+l}\right)}{P\left(s^{t+l}\right)}\right)=0,
\end{aligned}
$$

where $\Lambda\left(s^{t+l}\right)$ is given by: 


$$
\Lambda\left(s^{t+l}\right)=\beta^{t+l}\left(\frac{C\left(s^{t}\right)}{C\left(s^{t+l}\right)}\right) .
$$

Using equations (7), (8) and (9), the final goods $Y\left(s^{t}\right)$ produced in period $t$ are expressed with the wholesale goods produced in period $t$ as the following equation:

$$
\begin{aligned}
y\left(s^{t}\right) & =\int_{0}^{1} y\left(h, s^{t}\right) d h=\int_{0}^{1}\left(\frac{P\left(h, s^{t}\right)}{P\left(s^{t}\right)}\right)^{-\epsilon\left(s^{t}\right)} Y\left(s^{t}\right) d h \\
& =\left[\int_{0}^{1}\left(\frac{P_{t}\left(h, s^{t}\right)}{P\left(s^{t}\right)}\right)^{-\epsilon\left(s^{t}\right)} d h\right] Y\left(s^{t}\right) .
\end{aligned}
$$

Moreover, because of stickiness in the retail goods price, the aggregate price index for final goods $P\left(s^{t}\right)$ evolves according to the following law of motion:

$$
P\left(s^{t}\right)^{1-\epsilon\left(s^{t}\right)}=(1-\xi) P^{*}\left(h, s^{t}\right)^{1-\epsilon\left(s^{t}\right)}+\xi\left(\pi\left(s^{t-1}\right)^{\gamma_{p}} \bar{\pi}^{1-\gamma_{p}} P\left(s^{t-1}\right)\right)^{1-\epsilon\left(s^{t}\right)} .
$$

\section{Wholesalers}

The wholesalers produce wholesale goods $y_{t}\left(s^{t}\right)$ and sell them to the retailers with the relative price $1 / X_{t}\left(s^{t}\right)$. They hire three types of labor inputs, $H\left(s^{t}\right), H^{F}\left(s^{t}\right)$ and $H^{E}\left(s^{t}\right)$, and capital $K\left(s^{t-1}\right)$. These labor inputs are supplied by the household, FIs and entrepreneurs for wages $W\left(s^{t}\right), W^{F}\left(s^{t}\right)$ and $W^{E}\left(s^{t}\right)$, respectively. Capital is supplied by entrepreneurs with the rental price $R^{E}\left(s^{t}\right)$. At the end of each period, the capital is sold back to the entrepreneurs at price $Q\left(s^{t}\right)$. The maximization problem for the wholesaler is given by:

$$
\begin{aligned}
\max _{y\left(s^{t}\right), K\left(s^{t-1}\right), H\left(s^{t}\right), H^{F}\left(s^{t}\right), H^{E}\left(s^{t}\right)} & \frac{1}{X_{t}\left(s^{t}\right)} y_{t}\left(s^{t}\right)+Q\left(s^{t}\right) K\left(s^{t-1}\right)(1-\delta) \\
& -R^{E}\left(s^{t}\right) Q\left(s^{t-1}\right) K\left(s^{t-1}\right)-W\left(s^{t}\right) H\left(s^{t}\right) \\
& -W^{F}\left(s^{t}\right) H^{F}\left(s^{t}\right)-W^{E}\left(s^{t}\right) H^{E}\left(s^{t}\right),
\end{aligned}
$$

subject to:

$$
y\left(s^{t}\right)=A \exp \left(e^{A}\left(s^{t}\right)\right) K\left(s^{t-1}\right)^{\alpha} H\left(s^{t}\right)^{\left(1-\Omega_{F}-\Omega_{E}\right)(1-\alpha)} H^{F}\left(s^{t}\right)^{\Omega_{F}(1-\alpha)} H^{E}\left(s^{t}\right)^{\Omega_{E}(1-\alpha)},
$$

where $A \exp \left(e^{A}\left(s^{t}\right)\right)$ denotes the level of technology of wholesale production and $\delta \in(0,1], \alpha, \Omega_{F}$ and $\Omega_{E}$ are the depreciation rates of capital goods, the capital share, the share of the FIs' labor inputs and the share of entrepreneurial labor inputs, respectively.

\section{Capital producers}


The capital goods producers own the technology that converts final goods to capital goods. In each period, the capital goods producers purchase $I\left(s^{t}\right)$ amounts of final goods from the final goods producers. In addition, they purchase $K\left(s^{t-1}\right)(1-\delta)$ of used capital goods from the entrepreneurs at price $Q\left(s^{t}\right)$. They then produce new capital goods $K\left(s^{t}\right)$, using the technology $F_{I}$, and sell them in the competitive market at price $Q\left(s^{t}\right)$. Consequently, the capital goods producer's problem is to maximize the following profit function:

$$
\max _{I\left(s^{t}\right)} \sum_{l=0}^{\infty} \mathrm{E}_{t} \Lambda\left(s^{t+l}\right)\left[Q\left(s^{t+l}\right)\left(1-F_{I}\left(I\left(s^{t+l}\right), I\left(s^{t+l-1}\right)\right)\right) I\left(s^{t+l}\right)-I\left(s^{t+l}\right)\right],
$$

where $F_{I}$ is defined as follows:

$$
F_{I}\left(I\left(s^{t+l}\right), I\left(s^{t+l-1}\right)\right) \equiv \frac{\kappa}{2}\left(\frac{\exp \left(e^{I}\left(s^{t}\right)\right) I\left(s^{t+l}\right)}{I\left(s^{t+l-1}\right)}-1\right)^{2} .
$$

Note that $\kappa$ is a parameter that is associated with investment technology with an adjustment cost, where $e^{I}\left(s^{t}\right)$ is the shock to the adjustment cost. ${ }^{7}$ Here, the evolvement of the total capital available at period $t$ is described as:

$$
K\left(s^{t}\right)=\left(1-F_{I}\left(I\left(s^{t}\right), I\left(s^{t-1}\right)\right)\right) I\left(s^{t}\right)+(1-\delta) K\left(s^{t-1}\right) .
$$

\section{Government}

The government collects a lump-sum tax from the household $T\left(s^{t}\right)$, and spends $G\left(s^{t}\right)$. A budget balance is maintained for each period $t$. Thus, we have:

$$
G\left(s^{t}\right) \exp \left(e^{G}\left(s^{t}\right)\right)=T\left(s^{t}\right),
$$

where $e^{G}\left(s^{t}\right)$ is the stochastic component of government spending.

\section{Monetary authority}

In our baseline model, the monetary authority sets the nominal interest rate $R^{n}\left(s^{t}\right)$, according to a standard Taylor rule with inertia:

$$
R^{n}\left(s^{t}\right)=\theta R^{n}\left(s^{t-1}\right)+(1-\theta)\left(\phi_{\pi} \pi\left(s^{t}\right)+\phi_{y} \log \left(\frac{Y\left(s^{t}\right)}{Y}\right)\right)+e^{R}\left(s^{t}\right),
$$

\footnotetext{
${ }^{7}$ Equation (11) does not include a term for the purchase of the used capital $K\left(s^{t-1}\right)$ from the entrepreneurs at the end of the period. This is because we assume, following BGG, that the price of old capital that the entrepreneurs sell to the capital goods producers, say $\bar{Q}\left(s^{t}\right)$, is close to the price of the newly produced capital $Q\left(s^{t}\right)$ around the steady state.
} 
where $\theta$ is the autoregressive parameter of the policy rate, and $\phi_{\pi}$ and $\phi_{y}$ are the policy weight on inflation rate of final goods $\pi\left(s^{t}\right)$ and the output gap $\log \left(\frac{Y\left(s^{t}\right)}{Y}\right)$, respectively. Because the monetary authority determines the nominal interest rate, the real interest rate in the economy is given by the following Fisher equation:

$$
R\left(s^{t}\right) \equiv \mathrm{E}_{t}\left\{\frac{R^{n}\left(s^{t}\right)}{\pi\left(s^{t+1}\right)}\right\} .
$$

\section{Resource constraint}

The resource constraint for final goods is written as:

$$
\begin{aligned}
Y\left(s^{t}\right)= & C\left(s^{t}\right)+I\left(s^{t}\right)+G\left(s^{t}\right) \exp \left(e^{G}\left(s^{t}\right)\right) \\
& +\mu^{E} G^{E}\left(\bar{\omega}^{E}\left(s^{t}\right)\right) R^{E}\left(s^{t}\right) Q\left(s^{t-1}\right) K\left(s^{t-1}\right) \\
& +\mu^{F} G^{F}\left(\bar{\omega}^{F}\left(s^{t}\right)\right) R^{F}\left(s^{t}\right)\left(Q\left(s^{t-1}\right) K\left(s^{t-1}\right)-N^{E}\left(s^{t-1}\right)\right) \\
& +C^{F}\left(s^{t}\right)+C^{E}\left(s^{t}\right) .
\end{aligned}
$$

Note that the fourth and the fifth terms on the right-hand side of the equation correspond to the bankruptcy costs incurred by FIs and investors, respectively. The last two terms are the FIs' and entrepreneurs' consumption.

\section{Law of motion for exogenous variables}

There are six equations for the shock processes, $e^{A}\left(s^{t}\right), e^{I}\left(s^{t}\right), e^{B}\left(s^{t}\right), e^{G}\left(s^{t}\right), e^{P}\left(s^{t}\right)$ and $e^{R}\left(s^{t}\right)$, following processes as below:

$$
\begin{aligned}
& e^{A}\left(s^{t}\right)=\rho_{A} e^{A}\left(s^{t-1}\right)+\varepsilon^{A}\left(s^{t}\right), \\
& e^{I}\left(s^{t}\right)=\rho_{I} e^{I}\left(s^{t-1}\right)+\varepsilon^{I}\left(s^{t}\right), \\
& e^{B}\left(s^{t}\right)=\rho_{\beta} e^{B}\left(s^{t-1}\right)+\varepsilon^{\beta}\left(s^{t}\right), \\
& e^{G}\left(s^{t}\right)=\rho_{G} e^{G}\left(s^{t-1}\right)+\varepsilon^{G}\left(s^{t}\right), \\
& e^{P}\left(s^{t}\right)=\rho_{P} e^{P}\left(s^{t-1}\right)+\varepsilon^{P}\left(s^{t}\right), \\
& e^{R}\left(s^{t}\right)=\rho_{R} e^{R}\left(s^{t-1}\right)+\varepsilon^{R}\left(s^{t}\right),
\end{aligned}
$$

where $\rho_{A}, \rho_{I}, \rho_{B}, \rho_{G}, \rho_{P}$ and $\rho_{R} \in(0,1)$ are autoregressive roots of the exogenous variables, and $\varepsilon^{A}\left(s^{t}\right), \varepsilon^{I}\left(s^{t}\right), \varepsilon^{B}\left(s^{t}\right), \varepsilon^{G}\left(s^{t}\right), \varepsilon^{P}\left(s^{t}\right)$, and $\varepsilon^{R}\left(s^{t}\right)$ are innovations that are 
mutually independent, serially uncorrelated and normally distributed with mean zero and variances $\sigma_{A}^{2}, \sigma_{I}^{2}, \sigma_{\beta}^{2}, \sigma_{G}^{2}, \sigma_{P}^{2}$ and $\sigma_{R}^{2}$, respectively.

In addition, we consider shocks to the credit market. We assume that both FIs and entrepreneurs face an unexpected disruption (rise) in their net worth, denoted by $\varepsilon^{N_{F}}\left(s^{t}\right)$, $\varepsilon^{N_{E}}\left(s^{t}\right)$. These innovations directly affect net worth accumulation through equations (4) and (5). Following Gilchrist and Leahy (2002) and Nolan and Thoenissen (2009), we interpret these shocks as a shock to the efficiency of the contractual relations in the IF contract and the FE contract, respectively. ${ }^{8}$

\subsection{Equilibrium Condition}

An equilibrium consists of a set of prices, $\left\{P\left(h, s^{t}\right)\right.$ for $h \in[0,1], P\left(s^{t}\right), X\left(s^{t}\right), R\left(s^{t}\right)$, $R^{F}\left(s^{t}\right), R^{E}\left(s^{t}\right), W\left(s^{t}\right), W^{F}\left(s^{t}\right), W^{E}\left(s^{t}\right), Q\left(s^{t}\right), R^{F}\left(s^{t+1} \mid s^{t}\right), R^{E}\left(s^{t+1} \mid s^{t}\right), Z^{F}\left(s^{t+1} \mid s^{t}\right)$, $\left.Z^{E}\left(s^{t+1} \mid s^{t}\right)\right\}_{t=0}^{\infty}$, and the allocations $\left\{\bar{\omega}_{i}^{F}\left(s^{t+1} \mid s^{t}\right)\right\}_{t=0}^{\infty},\left\{\bar{\omega}_{j_{i}}^{E}\left(s^{t+1} \mid s^{t}\right)\right\}_{t=0}^{\infty},\left\{N_{i}^{F}\left(s^{t}\right)\right\}_{t=0}^{\infty}$, $\left\{N_{j_{i}}^{E}\left(s^{t}\right)\right\}_{t=0}^{\infty}\left\{\left\{y\left(h, s^{t}\right)\right), Y\left(h, s^{t}\right)\right.$ for $h \in[0,1], Y\left(s^{t}\right), C\left(s^{t}\right), D\left(s^{t}\right), I\left(s^{t}\right), K\left(s^{t}\right)$, $\left.\left.H\left(s^{t}\right)\right\}\right\}_{t=0}^{\infty}$, for a given government policy $\left\{i_{t}\left(s^{t}\right), G_{t}\left(s^{t}\right), T\left(s^{t}\right)\right\}_{t=0}^{\infty}$, realization of exogenous variables $\left\{\varepsilon^{A}\left(s^{t}\right), e^{B}\left(s^{t}\right), e^{G}\left(s^{t}\right), e^{I}\left(s^{t}\right), \varepsilon^{R}\left(s^{t}\right), \varepsilon^{P}\left(s^{t}\right), \varepsilon^{N_{E}}\left(s^{t}\right), \varepsilon^{N_{F}}\left(s^{t}\right)\right\}_{t=0}^{\infty}$ and initial conditions $N_{-1}^{F}, N_{-1}^{E}, K_{-1}$ such that for all $t$ and $h$ :

(i) a household maximizes its utility given the prices;

(ii) the FIs maximize their profits given the prices;

(iii) the entrepreneurs maximize their profits given the prices;

(iv) the final goods producers maximize their profits given the prices;

$(v)$ the retail goods producers maximize their profits given the input prices;

(vi) the wholesale goods producers maximize their profits given the prices;

(vii) the capital goods producers maximize their profits given the prices;

(viii) the government budget constraint holds; and

(ix) markets clear.

\section{Estimation}

Following Christensen and Dib (2008), we set some of the parameters following existing studies. These include: the quarterly discount factor $\beta$, the labor supply elasticity $\eta$, the capital share $\alpha$, the quarterly depreciation rate $\delta$ and the steady state share of government expenditure in total output $G / Y$. See Table 1 for the values of these parameters.

In addition, we calibrate six parameters for the credit contracts: the lenders' bankruptcy cost in the IF contract $\mu^{F}$, the lenders' bankruptcy cost in the FE contract $\mu^{E}$, the standard error of the idiosyncratic productivity shock in the FI sector $\sigma^{F}$, the standard error of the idiosyncratic productivity shock in the entrepreneurial sector $\sigma^{E}$, the

\footnotetext{
${ }^{8} \mathrm{CMR}$ and Nolan and Thoenissen (2009) assume that the exit ratio of entrepreneurs $\gamma^{E}$ obeys the stochastic law of motion, generating an unexpected change in entrepreneurial net worth. CMR interprets these shocks as a reduced form that describes an 'asset bubble' or 'irrational exuberance'.
} 
survival rate of FIs $\gamma^{F}$ and the survival rate of entrepreneurs $\gamma^{E}$, so these are consistent with the following equilibrium conditions at the steady state:

- (1) the risk spread, $R^{E}-R$, is 200 basis points annually;

- (2) the ratio of net worth held by FIs to the aggregate capital, $N^{F} / Q K$, is 0.1 , which is close to the actual value;

- (3) the ratio of net worth held by entrepreneurs to the aggregate capital, $N^{E} / Q K$, is 0.5 , the approximate value in the data;

- (4) the annualized failure rate of FIs is $2 \%$;

- (5) the annualized failure rate of entrepreneurs is $2 \%$; and

- (6) the FIs' lending spread $Z^{E}-Z^{F}$ is 230 basis points annually, which equals the historical average of the difference between the prime lending rate and the rate on six-month certificates of deposit from 1980 to 2006.

As for conditions (1), (3) and (5), we follow the settings in BGG. These conditions imply that the FIs' borrowing spread $Z^{F}-R$ equals 60 basis points annually, which turns out to be approximately equal to the average of the difference between the rate on six-month certificates of deposit and the six-month treasury bill rate from 1980 to 2006.

We estimate the other parts of the model using Bayesian methods. A sample of 200,000 draws was created, neglecting the first 100,000 draws. ${ }^{9}$ Estimated parameters are: the frequency of price adjustment $\xi$, the degree of price indexation $\gamma_{p}$, a parameter that controls the capital adjustment $\operatorname{cost} \kappa$, the coefficients of the policy rule $\theta, \phi_{\pi}$ and $\phi_{y}$, and the autoregressive parameters of the shock process $\rho_{A}, \rho_{I}, \rho_{B}, \rho_{G}, \rho_{R}$ and $\rho_{P}$.

\subsection{Data}

Our dataset includes seven time series for the U.S. economy from 1984Q1 to 2009Q2: namely, real GDP, real consumption, real investment, the log difference of the GDP deflator, the federal funds rate, the net worth-capital ratio of the FI sector and the net worth-capital ratio of the entrepreneurial sector. The last two variables are calculated from "Corporate equities + Equity in noncorporate business sector" held by the financial business sector divided by "Nonfinancial business total liabilities and equity" and "Corporate equities + Equity in noncorporate business sector" held by the nonfinancial business sector divided by "Nonfinancial business total liabilities and equity," respectively. Real GDP, real consumption, real investment and net worth are detrended with the Hodrick-Prescott filter with a smoothness parameter of 1,600. The federal funds rate and the log difference of the GDP deflator are deviations from their sample means. We depict all data series used in the estimation in Figure 1.

\footnotetext{
${ }^{9}$ All estimations are done with Dynare.
} 


\subsection{Prior and Posterior Distribution of the Parameters}

Table 2 reports the results of the parameter estimates with their prior distribution. We employ the priors of Smets and Wouters (2005) whenever possible. The adjustment cost parameter for investment $\kappa$ is normally distributed with a mean of 2.5 and a standard error of 1.0, the Calvo probability $\xi$ is beta distributed with a mean of 0.75 and a standard error of 0.2 , the degree of indexation to past inflation $\gamma_{p}$ is beta distributed with a mean of 0.5 and a standard error of 0.2 , the policy weight on the lagged policy rate $\theta$ is normally distributed with a mean of 0.75 and a standard error of 0.2 , the policy weight on the inflation $\phi_{\pi}$ is normally distributed with a mean of 1.5 and a standard error of 1.0 and the policy weight on the output gap $\phi_{y}$ is normally distributed with a mean of 0.125 and a standard error of 0.1 .

The priors on the stochastic processes of the exogenous shocks are set to follow an $\operatorname{AR}(1)$ process with autoregressive parameters $\rho_{A}, \rho_{I}, \rho_{B}, \rho_{G}, \rho_{R}$ and $\rho_{P}$, which are beta distributed with a mean of 0.6 and a standard deviation of 0.2 . The variances of the innovations in exogenous variables $\sigma_{A}^{2}, \sigma_{I}^{2}, \sigma_{\beta}^{2}, \sigma_{G}^{2}, \sigma_{N^{F}}^{2}, \sigma_{N^{E}}^{2}, \sigma_{P}^{2}$ and $\sigma_{R}^{2}$ are assumed to follow an inverse-gamma distribution with a mean of 0.1 .

The last three columns in Table 2 display the posterior mean and the confidence intervals of the model parameters. For the investment adjustment cost, we obtain $\kappa=$ 6.93. This value falls between the estimates of 0.65 (Meier and Muller, 2006) and 32.1 (Ireland, 2001) in existing studies. Our estimates display a moderate degree of nominal price rigidity, $\xi=0.60$ and $\gamma_{p}=0.20$. These values are smaller than the findings in Meier and Muller (2006). The estimated monetary policy rule exhibits aggressive reaction to current inflation $\phi_{\pi}=1.56$, with inertia of the interest rate $\theta=0.74$, and mild reaction to current output $\phi_{y}=0.01$. Table 2 also includes the shock processes of the eight exogenous variables. The productivity, investment adjustment cost and the preference processes are estimated to be persistent with $\mathrm{AR}(1)$ coefficients of $0.97,0.94$ and 0.86, respectively. The laws of motion for government expenditure, the policy rate and the price markups are relatively less persistent.

\subsection{External Finance Premium}

We first check the external validation of our estimation results using the spread data. To this end, we compare the model-implied time series for the FIs' lending spread $Z^{E}\left(s^{t+1} \mid s^{t}\right)-R\left(s^{t}\right)$ and the FIs' borrowing spread $Z^{F}\left(s^{t+1} \mid s^{t}\right)-R\left(s^{t}\right)$, with the corresponding data series. Although our estimated shocks are not constructed from the spread data, the model-implied series comove with the data. Figure 2 displays the series for the FIs' lending rate with the NBER business cycle period. We use the BAA rated corporate bonds-federal funds rate for the data. In general, these move together. They fall several quarters before the peak of the business cycle and rise during and after the recession. Their contemporaneous correlation over the sample period is +0.46 . In particular, in periods after 2000Q1, the model-implied series captures both the timing 
and magnitude of the data series very closely, yielding a contemporaneous correlation of $+0.73{ }^{10}$ Figure 3 displays the FIs' borrowing rate. We use the three-month certificate of deposit interest rate-federal funds rate for the data. On this occasion, the time series relationship is less clear, though the general pattern of movement is similar. The contemporaneous correlation between the two variables has the correct sign, and amounts to +0.25 over the sample period.

\subsection{Estimated Shocks to Credit Markets}

Next, we analyze the estimated shocks to the FIs' net worth and entrepreneurial net worth. Figure 4 displays the time series of the shocks, with a spread series of BAA rated corporate bonds-federal funds rate. ${ }^{11}$ As in the preceding section, this spread is one of the widely used indicators of credit market stress. The two shock series appear to be related to this indicator, in that both fall drastically around the recessions, especially those starting in 2001 and 2007. Interestingly, the shocks to the FIs' net worth are more volatile than those for entrepreneurial net worth, and are more significantly correlated with the spread. The contemporaneous correlation with the indicator for each shock is -0.36 and -0.14 , respectively. ${ }^{12}$ As illustrated in HSU (2009a, 2009b), the current model predicts that negative shocks to net worth lead to an increase in the external finance premium, and this is consistent with the observations in the figure. ${ }^{13}$

\subsection{Impulse Responses}

To illustrate the role of the shocks, including the shocks to the FIs' net worth, we plot the impulse responses of the key macroeconomic variables to the eight structural shocks. Figures 5, 6 and 7 show the response of investment, output and inflation, respectively, to positive shocks to preferences $\varepsilon^{B}\left(s^{t}\right)$, government expenditure $\varepsilon^{G}\left(s^{t}\right)$, investment adjustment $\operatorname{costs} \varepsilon^{I}\left(s^{t}\right)$, price markups $\varepsilon^{P}\left(s^{t}\right)$, monetary policy $\varepsilon^{R}\left(s^{t}\right)$, negative shocks

\footnotetext{
${ }^{10}$ There are several alternative indicators of the FIs' lending spread. In addition to the BAA rated corporate bonds-federal funds rate, we consider two alternative series: $(i)$ prime loan rate-federal funds rate, and (ii) BAA rated corporate bonds-AAA rated corporate bonds. The contemporaneous correlations between these measures and the model-implied FIs' lending rate are +0.10 and +0.60 , respectively. Clearly, the model-generated spread is only weakly correlated with the spread calculated using the prime loan rate. As discussed in De Grave (2008), one reason for this is because prime loan rates are applied to firms with high credit quality. If this is the case, it is possible that they then do not reflect the cost of external finance premium accurately when the credit market is under the stress.

${ }^{11}$ The shocks are three quarters moving-averaged, and the spread is on a year-on-year basis.

${ }^{12}$ We again study the properties of the estimated shocks with the alternative financial premium measures used above. The contemporaneous correlations between these measures and the shocks to the FIs' net worth (entrepreneurial net worth) are $-0.23(-0.12)$ and $-0.25(-0.20)$, respectively.

${ }^{13}$ Nolan and Thoenissen (2009) also compare the AAA rated bonds-three-month Treasury bill spread with their estimated financial shocks to evidence validity.
} 
to technology $\varepsilon^{A}\left(s^{t}\right)$, FI net worth $\varepsilon^{N_{F}}\left(s^{t}\right)$ and entrepreneurial net worth $\varepsilon^{N_{E}}\left(s^{t}\right)$ with the estimated size of one standard error.

Following an unexpected decline in FI and entrepreneurial net worth, investment, output and inflation fall. This is because the expected default probabilities of borrowers, $1-\int_{\bar{\omega}_{i}^{F}\left(s^{t+1} \mid s^{t}\right)}^{\infty} d F^{F}\left(\omega^{F}\right)$ and $1-\int_{\bar{\omega}_{i}^{E}\left(s^{t+1} \mid s^{t}\right)}^{\infty} d F^{E}\left(\omega^{E}\right)$, rise with the decline in borrowers' net worth. As a result, external financing cost $\mathrm{E}_{t} R^{E}\left(s^{t+1}\right) / R\left(s^{t}\right)$ increases, thereby reducing investment and output. Weakening demand towards capital goods $K\left(s^{t}\right)$ leads to a fall in the capital price $Q\left(s^{t}\right)$, providing deflationary pressure to the economy. The fall in the capital price results in a further decline in investment through the endogenous decline in the borrowers' net worth (the financial accelerator effect).

Among other shocks, shocks to investment adjustment costs bring about quantitatively large effects on investment and output. In contrast to shocks to net worth, a rise in investment adjustment costs directly increases investment cost through equation (12). Consequently, investment declines, reducing the capital price $Q\left(s^{t}\right)$, and this further deteriorates the net worth accumulation of the borrowing sectors. Adverse shocks to investment adjustment cost, FIs' net worth, and entrepreneurial net worth bring about the persistent economic downturn. Investment, output, and inflation continue to fall for several quarters, roughly about four quarters. After hitting the bottom, it takes far more than four quarters to go back to their steady state.

\subsection{Contribution of Shocks to FIs}

We now discuss the relative importance of shocks to the key macro variables. Figures 8, 9 and 10, respectively, display the historical contribution of each of the six structural shocks to investment, GDP and inflation. For illustrative purpose, we categorize these shocks in three broad categories. We include total factor productivity (TFP) shock $\varepsilon_{t}^{A}$, investment adjustment $\operatorname{cost}$ shock $\varepsilon_{t}^{I}$ and entrepreneurial net worth shock $\varepsilon_{t}^{N^{E}}$ in "shocks to the entrepreneurs" and the shocks to FIs' net worth in the "shocks to FIs." The rest of the shocks, including preference shocks $\varepsilon_{t}^{B}$, markup shocks $\varepsilon_{t}^{B}$, exogenous spending shocks $\varepsilon_{t}^{G}$ and monetary policy shocks $\varepsilon_{t}^{R}$, we categorize as "other shocks".

During the three recessions included in our sample period, the main sources of economic downturns are shocks to the entrepreneurs. As shown below, most arise from investment adjustment cost shocks. The quantitative roles of the shocks to FIs are relatively minor during the recessions. In the current financial crisis, covering the period from 2007Q4 to 2009Q2, for example, investment, output and inflation fall by $-20 \%$, $-5 \%$ and $-0.6 \%$, respectively, in terms of percent deviation from the mean. While shocks to FIs' net worth contribute only $24 \%, 10 \%$ and $20 \%$ to these declines, shocks to investment adjustment costs account for $53 \%, 51 \%$ and $48 \%$, respectively. Based on the other two recessions, however, it is also true that the contractionary impact of FI shocks lasts longer than shocks to entrepreneurs. In the recessions beginning in 1990 and 2001, these shocks continue to lower investment and output, even several quarters after the trough 
of the recessions. We also observe that the shocks to FIs are important in the inflation paths. During the sample period after year 2000, these are the one of the main sources of deflationary pressure in the economy.

To assess each shock quantitatively, we decompose the variations in investment, output and inflation into eight structural shocks. The results are reported in Table 3 for two different sample periods: $(i)$ the full sample period from 1984Q1 to 2009Q2, and ( $i i$ ) the subsample period from 1990Q1 to 2009Q2. ${ }^{14}$ Among the shocks to entrepreneurs, the shocks to capital adjustment costs are quantitatively important to all three endogenous variables. Most of the output variations and the bulk of the investment variations are especially explained by these shocks. ${ }^{15}$ The shocks to the credit market are particularly important to investment variation. Shocks to FIs account for 10-20\% and shocks to entrepreneurial net worth account for about $10 \%$ of investment variations. However, their impact on output and inflation are slightly smaller, compared with the impact on investment. In addition, our findings imply that the relative significance of shocks to FIs is time-varying. In evidence, the contribution of these shocks to investment variation during sample period $(\mathrm{ii})$ is twice as large as during sample period $(i) .{ }^{16}$

In the following sections, we conduct two sensitivity tests. We first ask how adding credit constraints to the FI sector affects the model's fit with the data. We develop models that abstract from the constraints and see which of these perform best. We then ask if our quantitative results are modified when we employ alternative estimation methodologies. Here we reformulate the estimations, changing the observable variables and the specification of shock processes.

\subsection{Sensitivity Analysis of Model Selection}

This section is devoted for checking the plausibility of our model. To do this, we conduct a comparative analysis using the current model and two alternative models. We estimate three models and see if credit frictions in the FI sector help bring the models closer to the data. The two models differ in the number of credit frictions involved. The first model is the "Non-FA model" in which no credit market imperfection prevails. Because credit constrained borrowers do not exist in this economy, the return to capital investment is

\footnotetext{
${ }^{14}$ In calculating the variance decompositions, we first calculate the volatility of the endogenous variable conditional on each of the shocks. We then sum these volatilities to calculate the share of each shock.

${ }^{15}$ Christensen and Dib (2008) report similar results. Based on the financial accelerator model, their estimate shows that $50-70 \%$ of output variations and about $90 \%$ of investment variations are accounted for by shocks to investment efficiency.

${ }^{16}$ In addition to the historical contribution, we quantify the importance of shocks to FI sector by comparing the estimated models. We estimate the parameters and log-likelihood of the model where all of the eight shocks are present (namely, benchmark), and the model where shocks to FIs' net worth are absent. All prior distributions for the latter model are the same as those assumed in benchmark. We obtain values of maximized log-likelihood, 2473.5 and 2360.8, respectively, indicating that shocks to FIs' net worth bring the model closer to the data.
} 
equalized to the households' receipts from investment. The second model is the "FAe model" in which credit constrained entrepreneurs are present, though no FIs are credit constrained. What distinguishes the current model from these models is the impact of the financial accelerator effect originating from the FI sector. In the FAe model, only the financial accelerator effect arising from the entrepreneurial sector is active. In the NonFA model, no financial accelerator mechanism is active. We provide a full description of the Non-FA and FAe models in Appendices B and C.

Making use of the same dataset $\left\{C_{t}, G D P_{t}, I_{t}, R_{t}^{n}\right\}_{t=1984 Q 1}^{2009 Q 2}$ for the three models, we estimate the model parameters $\left\{\kappa, \xi, \gamma_{p}, \theta, \phi_{\pi}, \phi_{y}\right\}$. For shock processes, we estimate $\left\{\rho_{A}\right.$, $\left.\rho_{I}, \rho_{B}, \rho_{G}, \rho_{R}, \rho_{P}, \sigma\left(\epsilon_{A}\right), \sigma\left(\epsilon_{I}\right), \sigma\left(\epsilon_{\beta}\right), \sigma\left(\epsilon_{G}\right), \sigma\left(\epsilon_{P}\right), \sigma\left(\epsilon_{R}\right)\right\}$ for Non-FA model, those with $\left\{\sigma\left(\epsilon^{N_{E}}\right)\right\}$ for FAe model and those with $\left\{\sigma\left(\epsilon^{N_{E}}\right), \sigma\left(\epsilon^{N_{F}}\right)\right\}$ for benchmark model. All estimations are conducted by Bayesian method. The parameters and shock processes that are not shared among the models are calibrated to the U.S. data. Table 4 reports the estimation results. It is notable that the values of the log-likelihood under the two alternative models are significantly lower than the value obtained under the benchmark. Therefore our benchmark model outperforms the other two models in explaining data. This indicates the importance of incorporating the credit constraint associated with the FI sector in explaining the data. ${ }^{17}$

\subsection{Sensitivity Analysis of Estimation Methodology}

In this section, we reexamine the results obtained from the above setting (hereafter, the benchmark model) along the three dimensions. First, we introduce an additional form of credit market shock to see how the inclusion of the other shocks affects the results. In the benchmark setting, the shocks originating from the credit market are shocks to either entrepreneurial or FI net worth. These shocks, however, cannot capture those that are independent from variations in net worth. For example, credit market stress can arise from the increase in uncertainty associated with the output productivity of borrowers. Following CMR, we now assume that the standard deviations of idiosyncratic productivity shocks of borrowers, named "riskiness" are time-variant, so that $\sigma_{t}^{F}$ and $\sigma_{t}^{E}$ obey the following laws of motion:

$$
\begin{aligned}
& \log \left(\frac{\sigma^{F}\left(s^{t}\right)}{\bar{\sigma}^{F}}\right)=\rho_{\sigma_{F}} \log \left(\frac{\sigma^{F}\left(s^{t-1}\right)}{\bar{\sigma}^{F}}\right)+\varepsilon^{\sigma_{F}}\left(s^{t}\right), \\
& \log \left(\frac{\sigma^{E}\left(s^{t}\right)}{\bar{\sigma}^{E}}\right)=\rho_{\sigma_{E}} \log \left(\frac{\sigma^{E}\left(s^{t-1}\right)}{\bar{\sigma}^{E}}\right)+\varepsilon_{t}^{\sigma_{E}}\left(s^{t}\right),
\end{aligned}
$$

where $\rho_{\sigma_{F}}$ and $\rho_{\sigma_{E}}$ are autoregressive parameters, $\varepsilon^{\sigma_{F}}\left(s^{t}\right)$ and $\varepsilon_{t}^{\sigma_{E}}\left(s^{t}\right)$ are the corresponding innovations and $\bar{\sigma}^{F}$ and $\bar{\sigma}^{E}$ are the steady state values of riskiness. Because the size

\footnotetext{
${ }^{17}$ Christensen and Dib (2008) conclude using the log-likelihood ratio test that their financial accelerator model outperforms the model that abstracts from the financial accelerator effect.
} 
of riskiness is independent of net worth, the cutoff values $\bar{\omega}^{F}\left(s^{t+1} \mid s^{t}\right)$ and $\bar{\omega}^{E}\left(s^{t+1} \mid s^{t}\right)$, and the external finance premium vary with riskiness, even with the same net worth. Second, we analyze how the choice of observable variables matters. Among the benchmark data sample $\left\{C_{t}, G D P_{t}, I_{t}, R_{t}^{n}, \pi_{t}, n_{t}^{F}, n_{t}^{E}\right\}_{t=1984 Q 1}^{2009 Q 2}$, we either drop $\left\{n_{t}^{F}, n_{t}^{E}\right\}_{t=1984 Q 1}^{2009 Q 2}$ or include alternative variables $\left\{Z_{t}^{F}-R_{t}, Z_{t}^{E}-R_{t}\right\}_{t=1984 Q 1}^{2009 Q 2}$ to the observables. While net worth and credit spreads are both considered important indicators of credit market stress, we choose not to employ the latter because they may contain measurement errors associated with the speculation of market participants. In fact, the choice of observable variables differs across the literature. For instance, while Christensen and Dib (2008) and De Grace (2008) employ neither series in estimating the model parameters, Nolan and Thoenissen (2009) use net worth, and CMR include both net worth and the external finance premium. We therefore check if our choice drastically affects the results in our model. Lastly, we reformulate the estimation by assuming the investment adjustment cost is constant throughout the sample period. As shown in the previous subsection, our benchmark estimation implies that adjustment cost shocks are the dominant source of U.S. business cycles.

We conduct five alternative estimations. In estimation II, we estimate shocks $\left\{\varepsilon^{A}\left(s^{t}\right)\right.$, $\left.\varepsilon^{I}\left(s^{t}\right), e^{B}\left(s^{t}\right), e^{G}\left(s^{t}\right), \varepsilon^{R}\left(s^{t}\right), \varepsilon^{P}\left(s^{t}\right), \varepsilon^{N_{E}}\left(s^{t}\right), \varepsilon^{N_{F}}\left(s^{t}\right), \varepsilon^{\sigma_{E}}\left(s^{t}\right), \varepsilon^{\sigma_{F}}\left(s^{t}\right)\right\}_{t=1984 Q 1}^{2009 Q 2}$, using the same dataset as the benchmark. Note that under this setting, borrowing sectors are subject to shocks to both their net worth and their riskiness. In estimation III, we estimate the same set of shocks as estimation II by using a larger number of observable variables $\left\{C_{t}, G D P_{t}, I_{t}, R_{t}^{n}, \pi_{t}, n_{t}^{F}, n_{t}^{E}, Z_{t}^{F}-R_{t}, Z_{t}^{E}-R_{t}\right\}_{t=1984 Q 1}^{2009 Q 2}$. These two estimations intend to capture the role of additional type of shocks to the credit market. In estimation IV, we drop $\left\{n_{t}^{F}, n_{t}^{E}\right\}_{t=1984 Q 1}^{20092}$ from the data sample and estimate the same shock as the benchmark. In estimation $\mathrm{V}$, we drop $\left\{n_{t}^{F}, n_{t}^{E}\right\}_{t=1984 Q 1}^{2009 Q 2}$ from the data sample again and estimate $\left\{\varepsilon^{A}\left(s^{t}\right), \varepsilon^{I}\left(s^{t}\right), e^{B}\left(s^{t}\right), e^{G}\left(s^{t}\right), \varepsilon^{R}\left(s^{t}\right), \varepsilon^{P}\left(s^{t}\right), \varepsilon^{N_{E}}\left(s^{t}\right), \varepsilon^{N_{F}}\left(s^{t}\right), \varepsilon^{\sigma_{E}}\left(s^{t}\right)\right.$, $\left.\varepsilon^{\sigma_{F}}\left(s^{t}\right)\right\}_{t=1984 Q 1}^{2009 Q 2}$. By dropping the variables for net worth, we see how our results obtained above can alter by the choice of observables. Estimation VI reports the case where there are no shocks in investment adjustment costs.

Tables 5, 6 and 7 display the variance decompositions of investment, output and inflation, respectively, based on the above four estimation methodologies. The first and second columns in the tables illustrate the role of the shocks to riskiness. The estimated contribution of riskiness shocks to the FI sector is significant, depending on the choice of observables. The first columns indicate that the riskiness shocks to FIs account for virtually none of the variation in investment and output. The second columns indicate, on the other hand, that shocks to FIs' riskiness contribute about $10 \%$ the investment variations. In contrast, the relative importance of the shocks to entrepreneurs decreases by the inclusion of riskiness shocks. As shown in third and fourth columns, the choice of observables matters to the estimation outcomes. Especially in estimation IV, where net worth-capital ratios are dropped from the sample, the contribution of shocks to FIs' net worth is very small. Even under these setting, however, more than $10 \%$ of investment 
variations and about $10 \%$ of output variations are explained by the shocks to FIs sector. The fifth column displays the consequences of dropping the investment adjustment cost shocks from the model. In this estimation, we obtain higher values for the contributions of the price markup shocks. The relative significance of the shocks to FIs is also affected. They now account for only $8-16 \%$ and $3-6 \%$ of the investment and output variation, respectively.

The exercises in this section indicate that the estimated importance of the shocks to the FI sector can differ depending on the estimation strategies and the sample period. For example, the estimated contribution of the shocks to output variation varies from about $3 \%$ to $20 \%$. However, as far as the investment series is concerned, shocks to the FI sector explain at least about $10 \%$ of the variation, suggesting their relative importance when compared with other shocks.

\section{Conclusion}

In this paper, we quantitatively assess the role of shocks to FI net worth in the U.S. business cycle. To this end, we estimated and simulated the financial accelerator model in HSU (2009b), in which FIs along with entrepreneurs are credit constrained. In this model, once net worth in the FI sector falls, the cost of external finance increases, and through the financial accelerator effect, reduces investment and output.

Employing Bayesian techniques, we distilled the shocks to the FI sector from the U.S. macroeconomic time series. Our results confirm the importance of shocks to the FI sector. We found that the shocks to FIs explain at least $10 \%$ of investment variation. Their impact is also persistent, lasting several quarters after the end of the recession. Other variables, such as GDP and inflation, are less affected by these shocks. In fact, during the most recent financial crisis starting in 2007, shocks to the FI sector account for $24 \%$ of the decline in investment, $10 \%$ of the decline in output and $20 \%$ of the decline in inflation. 


\section{A Credit Contract}

In this section, we discuss how the contents of the two credit contracts are determined by the profit maximization problem of the FIs. We first explain how the FIs earn profit from the credit contracts, and then explain the participation constraints of the other participants in the credit contracts.

In each period $t$, the expected net profit of an FI from the credit contracts is expressed by:

$$
\sum_{s^{t+1}} \Pi\left(s^{t+1} \mid s^{t}\right) \overbrace{\left[1-\Gamma^{F}\left(\bar{\omega}^{F}\left(s^{t+1} \mid s^{t}\right)\right)\right]}^{\text {share of FIs earnings received by FIs }} R^{F}\left(s^{t+1} \mid s^{t}\right)\left(Q_{t}\left(s^{t}\right) K\left(s^{t}\right)-N^{E}\left(s^{t}\right)\right),
$$

where $\Pi\left(s^{t+1} \mid s^{t}\right)$ is a probability weight for state $s^{t+1}$ for given state $s^{t}$. Here, the expected return on the loans to entrepreneurs, $R^{F}\left(s^{t+1} \mid s^{t}\right)$ is given by:

$$
\begin{gathered}
\overbrace{\left[\Gamma^{E}\left(\bar{\omega}^{E}\left(s^{t+1} \mid s^{t}\right)\right)-\mu^{E} G^{E}\left(\bar{\omega}^{E}\left(s^{t+1} \mid s^{t}\right)\right)\right]}^{\text {share of entrepreneurial earnings received by a FI }} R^{E}\left(s^{t+1} \mid s^{t}\right) Q\left(s^{t}\right) K\left(s^{t}\right) \\
\equiv R_{t}^{F}\left(s^{t+1} \mid s^{t}\right)\left(Q\left(s^{t}\right) K\left(s^{t}\right)-N^{E}\left(s^{t}\right)\right) \text { for } \forall s^{t+1} \mid s^{t} .
\end{gathered}
$$

This equation indicates that the two credit contracts determine the FIs' profits. In the FE contract, the FIs receive a portion of what entrepreneurs earn from their projects as their gross profit. In the IF contract, the FIs receive a portion of what they receive from the FE contract as their net profit, and pay the rest to the investors.

There are two participation constraints associated with both credit contracts. In the FE contract, the entrepreneurs' expected return is set as high as possible from their alternative means of investment. That is, instead of participating in the FE contract, entrepreneurs can purchase capital goods using their own net worth $N^{E}\left(s^{t}\right)$. Here, the expected return to this project equals $R^{E}\left(s^{t+1}\right) N^{E}\left(s^{t}\right)$. Consequently, the FE contract between an FI and an entrepreneur is agreed to only when the following inequality is expected to hold:

$$
\begin{gathered}
\overbrace{\left[1-\Gamma_{t}^{E}\left(\bar{\omega}^{E}\left(s^{t+1} \mid s^{t}\right)\right)\right]}^{\text {share of entrepreneurial earnings kept by entrepreneur }} \\
\geq R^{E}\left(s^{t+1} \mid s^{t}\right) N^{E}\left(s^{t}\right) \text { for } \forall s^{t+1} \mid s^{t} .
\end{gathered}
$$

We next consider a participation constraint of the investors in the IF contract. We assume that there is a risk free rate of return in the economy $R\left(s^{t}\right)$, and investors may 
alternatively invest in this asset. Consequently, for investors to profit from investment, the loans to the FIs must equal the opportunity cost of lending. That is:

$$
\begin{gathered}
\overbrace{\left[\Gamma^{F}\left(\bar{\omega}^{F}\left(s^{t+1} \mid s^{t}\right)\right)-\mu^{F} G^{F}\left(\bar{\omega}^{F}\left(s^{t+1} \mid s^{t}\right)\right)\right]}^{\text {share of FIs' earnings received by investors }} R^{F}\left(s^{t+1} \mid s^{t}\right)\left(Q\left(s^{t}\right) K\left(s^{t}\right)-N^{E}\left(s^{t}\right)\right) \\
\geq R\left(s^{t}\right)\left(Q\left(s^{t}\right) K\left(s^{t}\right)-N^{F}\left(s^{t}\right)-N^{E}\left(s^{t}\right)\right) .
\end{gathered}
$$

The FI maximizes its expected profit (25) by optimally choosing the variables $\bar{\omega}^{F}\left(s^{t+1} \mid s^{t}\right)$, $\bar{\omega}^{E}\left(s^{t+1} \mid s^{t}\right), K\left(s^{t}\right)$, subject to the investors' participation constraint (28) and entrepreneurial participation constraint (27). Combining the first-order conditions yields the following equation:

$$
\begin{aligned}
& 0=\sum_{s^{t+1} \mid s^{t}} \Pi\left(s^{t+1} \mid s^{t}\right)\left\{\left(1-\Gamma^{F}\left(\bar{\omega}^{F}\left(s^{t+1} \mid s^{t}\right)\right)\right) \Phi_{t}^{E}\left(s^{t+1} \mid s^{t}\right) R^{E}\left(s^{t+1} \mid s^{t}\right)\right. \\
& +\frac{\Gamma^{F}\left(\bar{\omega}^{F}\left(s^{t+1} \mid s^{t}\right)\right)}{\Phi^{\prime F}\left(s^{t+1} \mid s^{t}\right)} \Phi^{F}\left(s^{t+1} \mid s^{t}\right) \Phi^{E}\left(s^{t+1} \mid s^{t}\right) R_{t+1}^{E}\left(s^{t+1} \mid s^{t}\right) \\
& -\frac{\Gamma^{\prime F}\left(\bar{\omega}^{F}\left(s^{t+1} \mid s^{t}\right)\right)}{\Phi^{\prime F}\left(s^{t+1} \mid s^{t}\right)} R\left(s_{t}\right) \\
& +\frac{\left\{1-\Gamma^{F}\left(\bar{\omega}^{F}\left(s^{t+1} \mid s^{t}\right)\right)\right\} \Phi^{E}\left(s^{t+1} \mid s^{t}\right)}{\Gamma^{\prime} E\left(\bar{\omega}^{E}\left(s^{t+1} \mid s^{t}\right)\right)}\left(1-\Gamma^{E}\left(\bar{\omega}^{E}\left(s^{t+1} \mid s^{t}\right)\right)\right) R^{E}\left(s^{t+1} \mid s^{t}\right) \\
& \left.+\frac{\Gamma_{B}^{\prime}\left(\bar{\omega}^{F}\left(s^{t+1} \mid s^{t}\right)\right) \Phi^{F}\left(s^{t+1} \mid s^{t}\right) \Phi^{\prime E}\left(s^{t+1} \mid s^{t}\right)}{\Phi^{\prime F}\left(s^{t+1} \mid s^{t}\right) \Gamma^{\prime E}\left(\bar{\omega}^{E}\left(s^{t+1} \mid s^{t}\right)\right)}\left(1-\Gamma^{E}\left(\bar{\omega}^{E}\left(s^{t+1} \mid s^{t}\right)\right)\right) R^{E}\left(s^{t+1} \mid s^{t}\right)\right\} .
\end{aligned}
$$




\section{B Equilibrium Conditions of Benchmark Model}

In this appendix, we describe the equilibrium system of our benchmark model. We express these in five blocks of equations.

(1) Household's Problem and Resource Constraint

$$
\begin{gathered}
\frac{1}{C\left(s^{t}\right)}=E_{t}\left\{\beta \exp \left(e^{B\left(s^{t+1}\right)}\right) \frac{1}{C\left(s^{t+1}\right)} R_{t}\right\} \\
W\left(s^{t}\right)=\chi H\left(s^{t}\right)^{\frac{1}{\eta}} C\left(s^{t}\right), \\
R_{t}=\mathrm{E}_{t}\left\{\frac{R_{t}^{n}}{\pi_{t+1}}\right\} \\
Y\left(s^{t}\right)=\begin{array}{l}
C\left(s^{t}\right)+I\left(s^{t}\right)+G\left(s^{t}\right) \exp \left(e^{G}\left(s^{t}\right)\right) \\
+\mu^{E} G_{t}^{E}\left(\bar{\omega}^{E}\left(s^{t}\right)\right) R^{E}\left(s^{t}\right) Q\left(s^{t-1}\right) K\left(s^{t-1}\right) \\
+\mu^{F} G_{t}^{F}\left(\bar{\omega}^{F}\left(s^{t}\right)\right) R^{F}\left(s^{t}\right)\left(Q\left(s^{t-1}\right) K\left(s^{t-1}\right)-N^{E}\left(s^{t-1}\right)\right) \\
+C^{F}\left(s^{t}\right)+C^{E}\left(s^{t}\right),
\end{array}
\end{gathered}
$$

with:

$$
\begin{aligned}
C^{F}\left(s^{t}\right) \equiv & \left(1-\gamma^{F}\right)\left(1-\Gamma^{F}\left(\bar{\omega}^{F}\left(s^{t+1}\right)\right)\right)\left(\Gamma^{E}\left(\bar{\omega}^{E}\left(s^{t+1}\right)\right)-\mu^{E} G^{E}\left(\bar{\omega}^{E}\left(s^{t+1}\right)\right)\right) \\
& \cdot R^{E}\left(s^{t+1}\right) Q\left(s^{t}\right) K\left(s^{t}\right) \\
C^{E}\left(s^{t}\right) \equiv & \left(1-\Gamma^{E}\left(\bar{\omega}^{E}\left(s^{t+1}\right)\right)\right) R^{E}\left(s^{t+1}\right) Q\left(s^{t}\right) K\left(s^{t}\right) .
\end{aligned}
$$

\section{(2) Firms' Problems}

$$
Y\left(s^{t}\right)=\frac{A \exp \left(e^{A}\left(s^{t}\right)\right) K\left(s^{t-1}\right)^{\alpha} H\left(s^{t}\right)^{\left(1-\Omega_{F}-\Omega_{E}\right)(1-\alpha)} H^{F}\left(s^{t}\right)^{\Omega_{F}(1-\alpha)} H^{E}\left(s^{t}\right)^{\Omega_{E}(1-\alpha)}}{\Delta_{p}\left(s^{t}\right)}
$$


with:

$$
\begin{aligned}
& \Delta_{p}\left(s^{t}\right)=(1-\xi)\left(\frac{K_{p}\left(s^{t}\right)}{F_{p}\left(s^{t}\right)}\right)^{-\epsilon\left(s^{t}\right)}+\xi\left(\frac{\pi\left(s^{t-1}\right)^{\gamma_{p}}}{\pi\left(s^{t}\right)}\right)^{-\epsilon\left(s^{t}\right)} \Delta_{p}\left(s^{t-1}\right), \\
& F_{p}\left(s^{t}\right)=1+\xi \beta \exp \left(e^{B\left(s^{t+1}\right)}\right) \frac{C\left(s^{t}\right) Y\left(s^{t+1}\right)}{C\left(s^{t+1}\right) Y\left(s^{t}\right)}\left(\frac{\pi\left(s^{t}\right)^{\gamma_{p}}}{\pi\left(s^{t+1}\right)}\right)^{1-\epsilon\left(s^{t}\right)} F_{p}\left(s^{t+1}\right), \\
& K_{p}\left(s^{t}\right)=\frac{\epsilon\left(s^{t}\right)}{\epsilon\left(s^{t}\right)-1} M C\left(s^{t}\right)+\xi \beta \exp \left(e^{B\left(s^{t+1}\right)}\right) \frac{C\left(s^{t}\right) Y\left(s^{t+1}\right)}{C\left(s^{t+1}\right) Y\left(s^{t}\right)}\left(\frac{\pi\left(s^{t}\right)^{\gamma_{p}}}{\pi\left(s^{t+1}\right)}\right)^{-\epsilon\left(s^{t}\right)} K_{p}\left(s^{t+1}\right), \\
& \begin{aligned}
H\left(s^{t}\right) W\left(s^{t}\right)= & A \exp \left(e^{A}\left(s^{t}\right)\right) K\left(s^{t-1}\right)^{\alpha} H\left(s^{t}\right)^{\left(1-\Omega_{F}-\Omega_{E}\right)(1-\alpha)} H^{F}\left(s^{t}\right)^{\Omega_{F}(1-\alpha)} H^{E}\left(s^{t}\right)^{\Omega_{E}(1-\alpha)} \\
& \cdot M C\left(s^{t}\right)(1-\alpha)\left(1-\Omega_{F}-\Omega_{E}\right),
\end{aligned} \\
& \mathrm{E}_{t} R^{E}\left(s^{t}\right)=\mathrm{E}_{t} \frac{\alpha Y\left(s^{t}\right) / K\left(s^{t}\right)+Q\left(s^{t+1}\right)(1-\delta)}{Q\left(s^{t}\right)}, \\
& Q\left(s^{t}\right)\left(1-0.5 \kappa\left(\frac{I\left(s^{t}\right) \exp \left(e^{I}\left(s^{t}\right)\right)}{I\left(s^{t-1}\right)}-1\right)^{2}\right) \\
& -Q\left(s^{t}\right)\left(\kappa\left(\frac{I\left(s^{t}\right) \exp \left(e^{I}\left(s^{t}\right)\right)}{I\left(s^{t-1}\right)}\right)\left(\frac{I\left(s^{t}\right) \exp \left(e^{I}\left(s^{t}\right)\right)}{I\left(s^{t-1}\right)}-1\right)\right)-1 \\
& =\mathrm{E}_{t}\left\{\beta \exp \left(e^{B\left(s^{t+1}\right)}\right) \frac{C\left(s^{t}\right) Q\left(s^{t+1}\right)}{C\left(s^{t+1}\right)} \kappa\left(\frac{I\left(s^{t+1}\right) \exp \left(e^{I}\left(s^{t+1}\right)\right)}{I\left(s^{t}\right)}\right)^{2}\left(\frac{I\left(s^{t+1}\right)}{I\left(s^{t}\right)}-1\right) \exp \left(e^{I}\left(s^{t+1}\right)\right)\right\} .
\end{aligned}
$$

\section{(3) FIs' Problems}

Equilibrium conditions for credit contracts are given by (28), (27) and (29), and the following equations:

$$
G^{F}\left(\bar{\omega}_{t}^{F}\right)=\frac{1}{\sqrt{2 \pi}} \int_{-\infty}^{\frac{\log \bar{\omega}_{t}^{F}-0.5 \sigma_{F}^{2}}{\sigma_{F}}} \exp \left(-\frac{v_{F}^{2}}{2}\right) d v_{F}
$$




$$
\begin{aligned}
& G^{E}\left(\bar{\omega}_{t}^{E}\right)=\frac{1}{\sqrt{2 \pi}} \int_{-\infty}^{\frac{\log \bar{\omega}_{t}^{E}-0.5 \sigma_{E}^{2}}{\sigma_{E}}} \exp \left(-\frac{v_{E}^{2}}{2}\right) d v_{E} \\
& G^{\prime F}\left(\bar{\omega}_{t}^{F}\right)=\left(\frac{1}{\sqrt{2 \pi}}\right)\left(\frac{1}{\bar{\omega}_{t}^{F} \sigma_{F}}\right) \exp \left(-.5\left(\frac{\log \bar{\omega}_{t}^{F}-0.5 \sigma_{F}^{2}}{\sigma_{F}}\right)^{2}\right) \\
& G^{\prime E}\left(\bar{\omega}_{t}^{E}\right)=\left(\frac{1}{\sqrt{2 \pi}}\right)\left(\frac{1}{\bar{\omega}_{t}^{E} \sigma_{E}}\right) \exp \left(-.5\left(\frac{\log \bar{\omega}_{t}^{E}-0.5 \sigma_{E}^{2}}{\sigma_{E}}\right)^{2}\right) \\
& \Gamma^{F}\left(\bar{\omega}_{t}^{F}\right)=\frac{1}{\sqrt{2 \pi}} \int_{-\infty}^{\frac{\log \bar{\omega}_{t}^{F}-0.5 \sigma_{F}^{2}}{\sigma_{F}}} \exp \left(-\frac{v_{F}^{2}}{2}\right) d v_{F}+\frac{\bar{\omega}_{t}^{F}}{\sqrt{2 \pi}} \int_{\frac{\log \bar{\omega}_{t}^{F}+0.5 \sigma_{F}^{2}}{\sigma_{F}}}^{\infty} \exp \left(-\frac{v_{F}^{2}}{2}\right) d v_{F} \\
& \Gamma^{E}\left(\bar{\omega}_{t}^{E}\right)=\frac{1}{\sqrt{2 \pi}} \int_{-\infty}^{\frac{\log \bar{\omega}_{t}^{E}-0.5 \sigma_{E}^{2}}{\sigma_{E}}} \exp \left(-\frac{x^{2}}{2}\right) d x+\frac{\bar{\omega}_{t}^{E}}{\sqrt{2 \pi}} \int_{\frac{\log \bar{\omega}_{t}^{E}+0.5 \sigma_{E}^{2}}{\sigma_{E}}}^{\infty} \exp \left(-\frac{v_{E}^{2}}{2}\right) d v_{E}, \\
& \Gamma^{\prime F}\left(\bar{\omega}_{t}^{F}\right)=\frac{1}{\sqrt{2 \pi} \bar{\omega}_{t}^{F} \sigma_{F}} \exp \left(-.5\left(\frac{\log \bar{\omega}_{t}^{F}-0.5 \sigma_{F}^{2}}{\sigma_{F}}\right)^{2}\right) d x \\
& +\frac{1}{\sqrt{2 \pi}} \int_{\frac{\log \bar{\omega}_{t}^{F}+0.5 \sigma_{F}^{2}}{\sigma_{F}}}^{\infty} \exp \left(-\frac{v_{F}^{2}}{2}\right) d v_{F} \\
& -\frac{1}{\sqrt{2 \pi} \sigma_{F}} \exp \left(-\frac{\left(\frac{\log \bar{\omega}_{t}^{F}+0.5 \sigma_{F}^{2}}{\sigma_{F}}\right)^{2}}{2}\right) d x \\
& \Gamma^{\prime E}\left(\bar{\omega}_{t}^{E}\right)=\frac{1}{\sqrt{2 \pi} \bar{\omega}_{t}^{E} \sigma_{E}} \exp \left(-.5\left(\frac{\log \bar{\omega}_{t}^{E}-0.5 \sigma_{E}^{2}}{\sigma_{E}}\right)^{2}\right) d x \\
& +\frac{1}{\sqrt{2 \pi}} \int_{\frac{\log \bar{\omega}_{t}^{E}+0.5 \sigma_{E}^{2}}{\sigma_{E}}}^{\infty} \exp \left(-\frac{v_{E}^{2}}{2}\right) d v_{E} \\
& -\frac{1}{\sqrt{2 \pi} \sigma_{E}} \exp \left(-.5\left(\frac{\log \bar{\omega}_{t}^{E}+0.5 \sigma_{E}^{2}}{\sigma_{E}}\right)^{2}\right) d x
\end{aligned}
$$




$$
\begin{gathered}
{\left[\Gamma^{E}\left(\bar{\omega}^{E}\left(s^{t+1} \mid s^{t}\right)\right)-\mu^{E} G^{E}\left(\bar{\omega}^{E}\left(s^{t+1} \mid s^{t}\right)\right)\right] R^{E}\left(s^{t+1} \mid s^{t}\right) Q\left(s^{t}\right) K\left(s^{t}\right)} \\
=R_{t}^{F}\left(s^{t+1} \mid s^{t}\right)\left(Q\left(s^{t}\right) K\left(s^{t}\right)-N^{E}\left(s^{t}\right)\right) .
\end{gathered}
$$

\section{(4) Laws of Motion of State Variables}

$$
\begin{gathered}
K\left(s^{t}\right)=\left(1-0.5 \kappa\left(\frac{I\left(s^{t}\right) \exp \left(e^{I}\left(s^{t}\right)\right)}{I\left(s^{t-1}\right)}\right)^{2}\right) I\left(s^{t}\right)+(1-\delta) K\left(s^{t-1}\right) \\
N^{F}\left(s^{t+1}\right)=\gamma^{F} V^{F}\left(s^{t}\right)+W^{F}\left(s^{t}\right) \\
N^{E}\left(s^{t+1}\right)=\gamma^{E} V^{E}\left(s^{t}\right)+W^{E}\left(s^{t}\right)
\end{gathered}
$$

with:

$$
\begin{aligned}
V^{F}\left(s^{t}\right) \equiv & \left(1-\Gamma^{F}\left(\bar{\omega}^{F}\left(s^{t+1}\right)\right)\right)\left(\Gamma^{E}\left(\bar{\omega}^{E}\left(s^{t+1}\right)\right)-\mu^{E} G^{E}\left(\bar{\omega}^{E}\left(s^{t+1}\right)\right)\right) \\
& \cdot R^{E}\left(s^{t+1}\right) Q\left(s^{t}\right) K\left(s^{t}\right), \\
V^{E}\left(s^{t}\right) \equiv & \left(1-\Gamma^{E}\left(\bar{\omega}^{E}\left(s^{t+1}\right)\right)\right) R^{E}\left(s^{t+1}\right) Q\left(s^{t}\right) K\left(s^{t}\right), \\
W^{F}\left(s^{t}\right) \equiv & (1-\alpha) \Omega_{F} Y\left(s^{t}\right), \\
W^{E}\left(s^{t}\right) \equiv & (1-\alpha) \Omega_{E} Y\left(s^{t}\right) .
\end{aligned}
$$

(5) Policies and Shock Process

Policies for the shock process are given by equations (13), (14), (17), (18), (19), (20), (21) and (22). 


\section{Equilibrium Conditions of Alternative Models}

In addition to the benchmark model, we consider two alternative models for comparative convenience. The first is the Non-FA model in which no financial accelerator mechanism is incorporated. The equilibrium conditions under this model are given by equations (30), (31), (32), (34), (35), (36), (37), (47), (13), (14), (17), (18), (19), (20), (21) and (22), and the following equations instead of equations (33) and (36) under the benchmark model, respectively:

$$
\begin{aligned}
& Y\left(s^{t}\right)=C\left(s^{t}\right)+I\left(s^{t}\right)+G\left(s^{t}\right) \exp \left(e^{G}\left(s^{t}\right)\right), \\
& R\left(s^{t}\right)=\mathrm{E}_{t} \frac{\alpha Y\left(s^{t}\right) / K\left(s^{t}\right)+Q\left(s^{t+1}\right)(1-\delta)}{Q\left(s^{t}\right)} .
\end{aligned}
$$

The second model is the FAe model in which only entrepreneurs are credit constrained. The equilibrium conditions in this model are given by equations (30), (31), (32), (34), (35), (36), (36), (37), (39), (41), (43), (45), (47), (5), (13), (14), (17), (18), (19), (20), (21) and (22), and the following three equations instead of equations (29), (33) and (36) under the benchmark model, respectively:

$$
\begin{gathered}
0=\sum_{s^{t+1} \mid s^{t}} \Pi\left(s^{t+1} \mid s^{t}\right)\left(1-\Gamma^{E}\left(\bar{\omega}^{E}\left(s^{t+1} \mid s^{t}\right)\right)\right) R^{E}\left(s^{t+1} \mid s^{t}\right) \\
+\frac{\Gamma^{E}\left(\bar{\omega}^{F}\left(s^{t+1} \mid s^{t}\right)\right)}{\Phi^{\prime E}\left(s^{t+1} \mid s^{t}\right)} \Phi^{E}\left(s^{t+1} \mid s^{t}\right) R_{t+1}^{E}\left(s^{t+1} \mid s^{t}\right)-\frac{\Gamma^{E}\left(\bar{\omega}^{E}\left(s^{t+1} \mid s^{t}\right)\right)}{\Phi^{\prime E}\left(s^{t+1} \mid s^{t}\right)} \Phi^{E}\left(s^{t+1} \mid s^{t}\right) R\left(s_{t}\right) \\
Y\left(s^{t}\right)= \\
\quad C\left(s^{t}\right)+I\left(s^{t}\right)+G\left(s^{t}\right) \exp \left(e^{G}\left(s^{t}\right)\right) \\
+\mu^{E} G^{E}\left(\bar{\omega}^{E}\left(s^{t}\right)\right) R^{E}\left(s^{t}\right) Q\left(s^{t-1}\right) K\left(s^{t-1}\right)+C^{E}\left(s^{t}\right)
\end{gathered}
$$

with:

$$
\begin{gathered}
C^{E}\left(s^{t}\right) \equiv\left(1-\Gamma^{E}\left(\bar{\omega}^{E}\left(s^{t+1}\right)\right)\right) R^{E}\left(s^{t+1}\right) Q\left(s^{t}\right) K\left(s^{t}\right) \\
{\left[\Gamma^{E}\left(\bar{\omega}^{E}\left(s^{t+1} \mid s^{t}\right)\right)-\mu^{E} G^{E}\left(\bar{\omega}^{E}\left(s^{t+1} \mid s^{t}\right)\right)\right] R^{E}\left(s^{t+1} \mid s^{t}\right) Q\left(s^{t}\right) K\left(s^{t}\right)} \\
=R_{t}\left(s^{t+1} \mid s^{t}\right)\left(Q\left(s^{t}\right) K\left(s^{t}\right)-N^{E}\left(s^{t}\right)\right) .
\end{gathered}
$$




\section{References}

[1] Aikman, D. and M. Paustian (2006). "Bank Capital, Asset Prices and Monetary Policy," Bank of England Working Papers 305, Bank of England.

[2] Anari A., J. Kolari and J. Mason (2005). "Bank Asset Liquidation and the Propagation of the U.S. Great Depression." Journal of Money, Credit, and Banking, Vol. 37, No. 4, pp. $753-773$.

[3] Ashcraft, A. B. (2005). "Are Banks Really Special? New Evidence from the FDICInduced Failure of Healthy Banks," American Economic Review, Vol. 95 No. 5, pp. $1712-1730$.

[4] Bernanke, B. S., M. Gertler and S. Gilchrist (1999). "The Financial Accelerator in a Quantitative Business Cycle Framework," in Handbook of Macroeconomics, J. B. Taylor and M. Woodford (eds.), Vol. 1, chapter 21, pp. 1341-1393.

[5] Calomiris, C. W., and B. Wilson (2003). "Consequences of Bank Distress during the Great Depression," American Economic Review, Vol. 93, pp. 937-947.

[6] Calvo, G.A. (1983). "Staggered prices in a utility-maximizing framework," Journal of Monetary Economics 12, 383-398.

[7] Christensen, I. and A. Dib (2008). "The Financial Accelerator in an Estimated New Keynesian Model." Review of Economic Dynamics. Vol. 11, No. 1, pp. 155-178.

[8] Chen, N. K. (2001). "Bank Net Worth, Asset Prices and Economic Activity," Journal of Monetary Economics, Vol. 48, No. 2, pp.415-436.

[9] Christiano, L., R. Motto, and M. Rostagno (2003). "The great depression and the Friedman-Schwartz hypothesis," Journal of Money, Credit and Banking $35(6,2)$, 1119-1198.

[10] Christiano, L., R. Motto, and M. Rostagno (2007). "Financial factors in business cycles," Manuscript

[11] Christiano, L., R. Motto, and M. Rostagno (2008). "Shocks, structures or monetary policies? The Euro Area and US after 2001," Journal of Economic Dynamics and Control, Vol. 32, pp. 2476-2506.

[12] De Graeve, F. (2008). "The external finance premium and the macroeconomy: US post-WWII evidence," Journal of Economic Dynamics and Control, Vol. 32, pp.3415-3440.

[13] Gilchrist, S. and J. V. Leahy (2002). "Monetary Policy and Asset Prices," Journal of Monetary Economics, Vol. 49, No. 1, pp. 75-97. 
[14] Gilchrist, S., V. Yankov, and E. Zakrajsek (2009). Credit Risks and the Macroeconomy: Evidence from an Estimated DSGE Model. Unpublished. manuscript, Boston University and Federal Reserve Board.

[15] Hirakata, N., N. Sudo and K. Ueda (2009a). "Chained Credit Contracts and Financial Accelerators," IMES Discussion Paper 2009-E-30, Institute for Monetary and Economic Studies, Bank of Japan;

[16] Hirakata, N., N. Sudo and K. Ueda (2009b). "Capital Injection, Monetary Policy and Financial Accelerators," Draft, Bank of Japan.

[17] Holmstrom, B. and J. Tirole (1997). "Financial Intermediation, Loanable Funds, and the Real Sector," Quarterly Journal of Economics, Vol. 112, No. 3, pp. 663-691.

[18] Meh C., and K. Moran (2004). "Bank Capital, Agency Costs, and Monetary Policy," Working Papers 04-6, Bank of Canada.

[19] Meier, A. and G. J. Muller (2006). "Fleshing out the Monetary Transmission Mechanism: Output Composition and the Role of Financial Frictions." Journal of Money, Credit, Banking Vol. 38, pp. 1999-2133.

[20] Nolan, C. and C. Thoenissen (2009). "Financial Shocks and the US Business Cycle," Journal of Monetary Economics, Vol. 56, No. 4, pp. 596-604.

[21] Peek, J. and E. S. Rosengren (1997). "The International Transmission of Financial Shocks: Case of Japan," American Economic Review, Vol. 87, No. 4, pp. 625-638.

[22] Peek, J. and E. S. Rosengren (2000). "Collateral Damage: Effects of the Japanese Bank Crisis on Real Activity in the United States," American Economic Review, Vol. 97, No. 3, pp. 30-45.

[23] Smets, F and R. Wouters (2005). "Shocks and Frictions in US Business Cycles: A Bayesian DSGE Approach," American Economic Review, Vol. 90, No. 1, pp. 586606. 

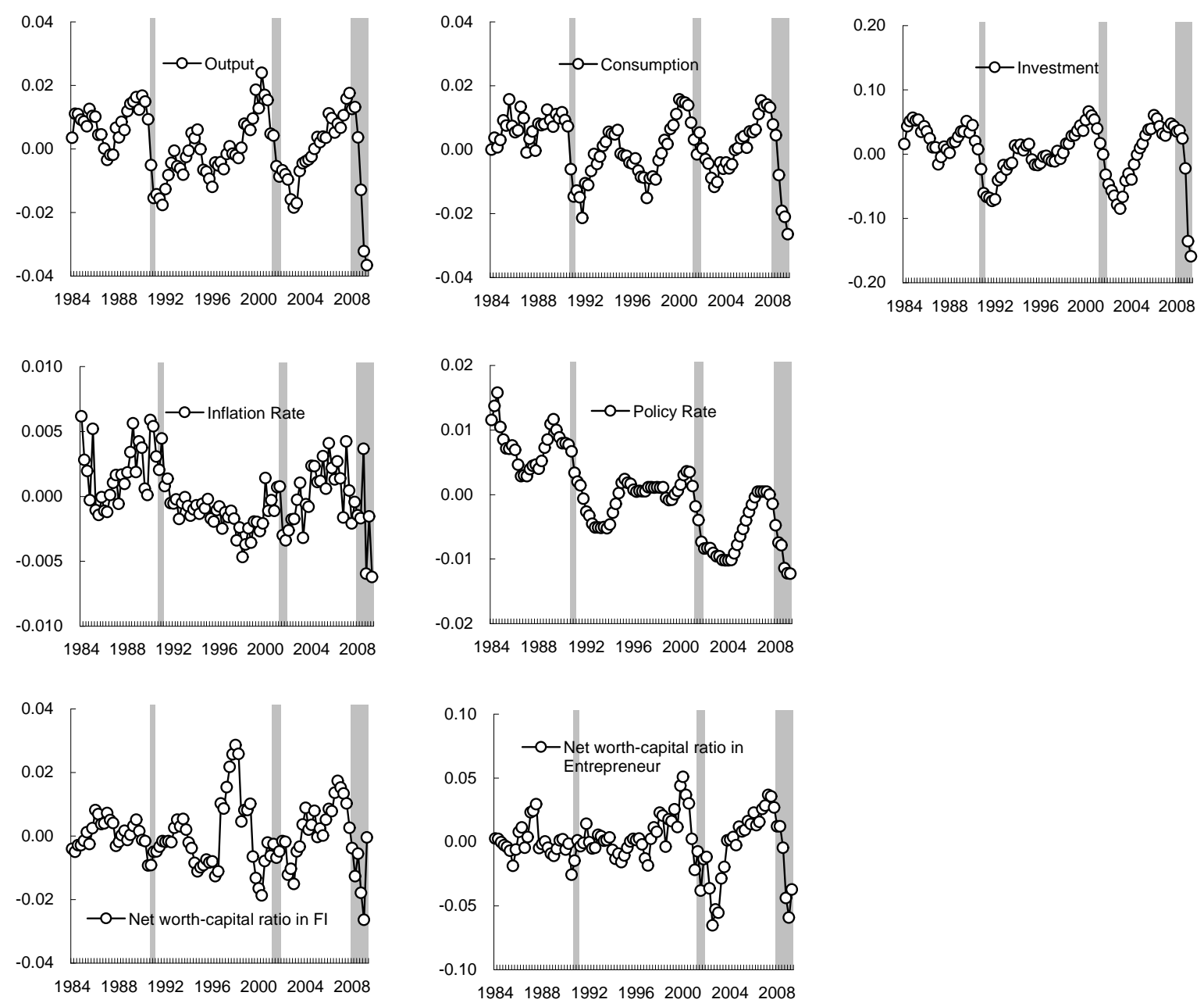

Figure 1: Time series of observables from 1984Q1 to 2009Q2. Shaded quarters are those between the peak and trough of NBER business cycle. 


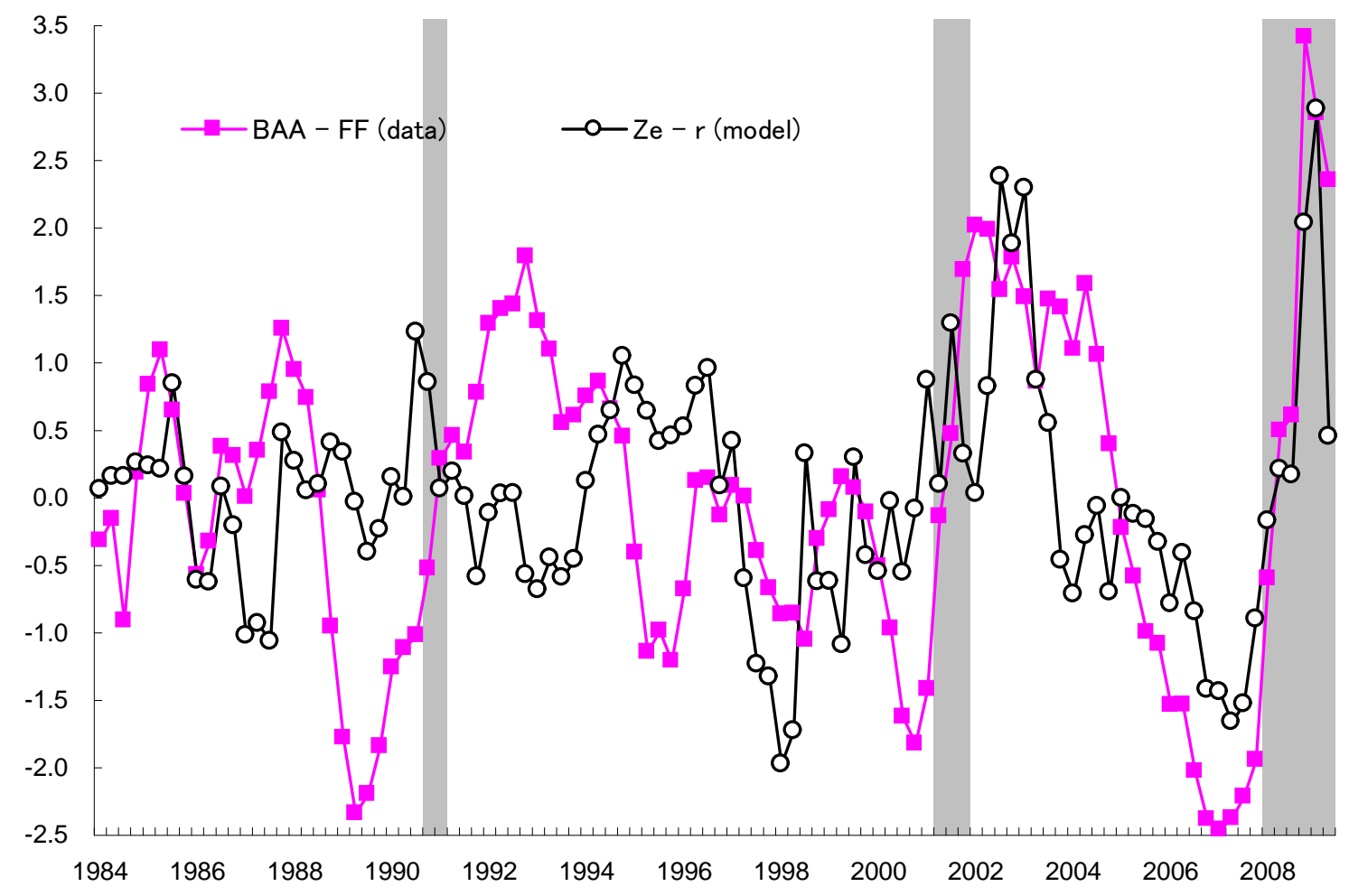

Figure 2: The model-generated series of FIs' lending spread $Z^{E}\left(s^{t+1} \mid s^{t}\right)-R\left(s^{t}\right)$, and a spread between BAA rated corporate bonds and the federal funds rate. All series are HP-filtered. Shaded quarters are those between the peak and trough of NBER business cycle. 


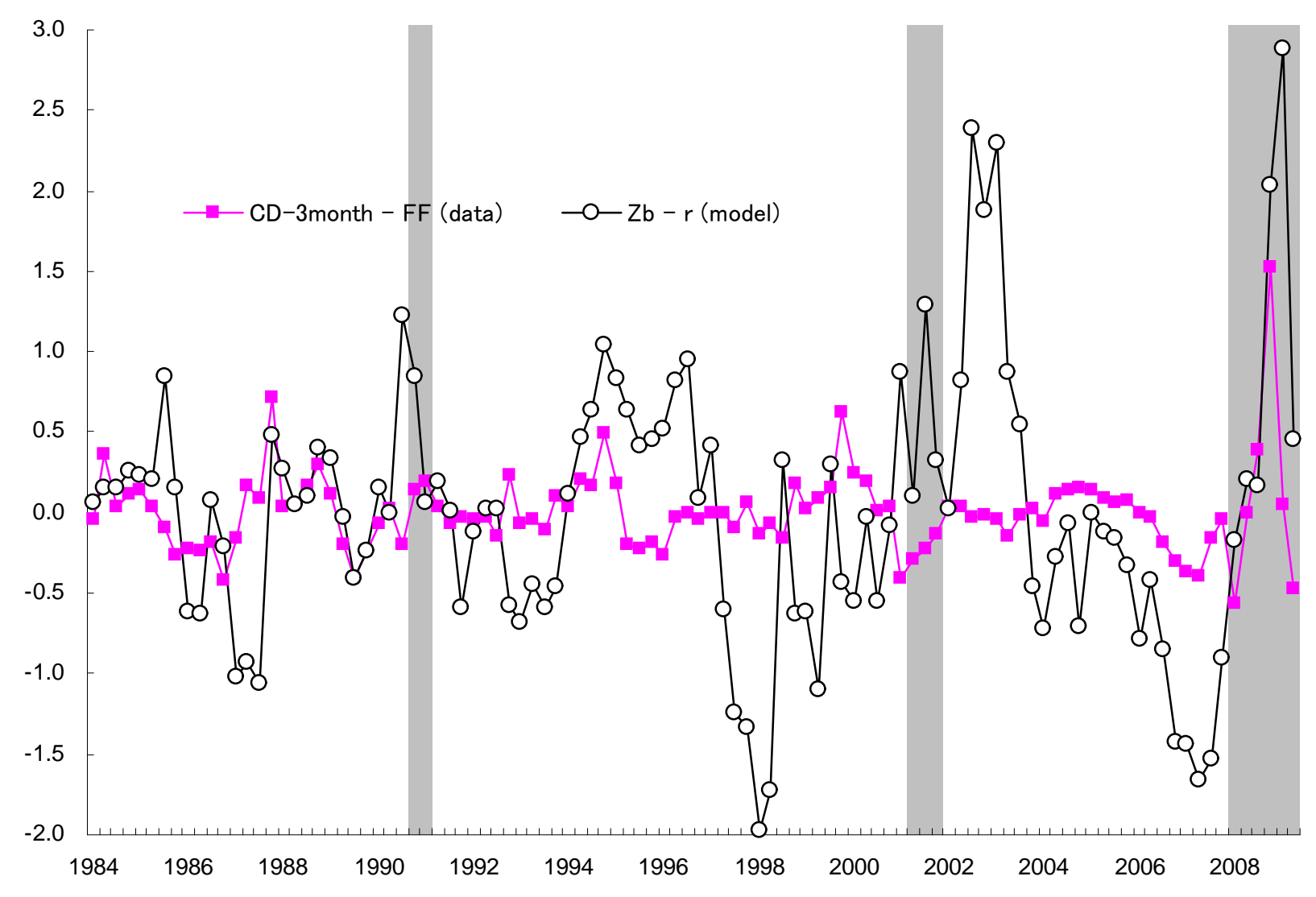

Figure 3: The model-generated series of FIs' borrowing spread $Z^{F}\left(s^{t+1} \mid s^{t}\right)-R\left(s^{t}\right)$, and a spread between CD three months and federal funds rate. All series are HP-filtered. Shaded quarters are those between the peak and trough of NBER business cycle. 


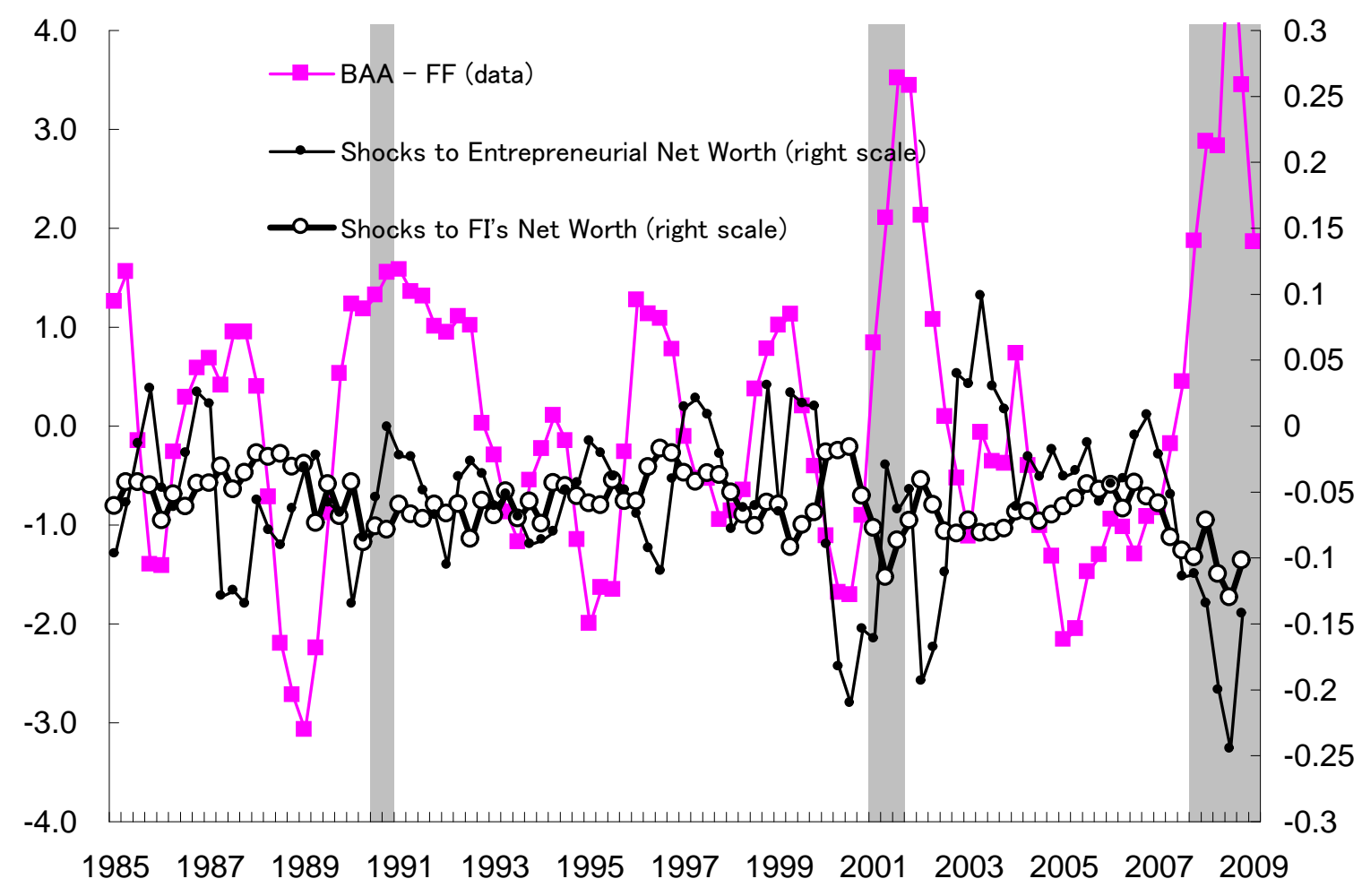

Figure 4: The estimated shocks and a measure of external finance premium (a spread between BAA rated corporate bonds and the federal funds rate). All series are HP-filtered, and spread series is year-on-year basis. Shaded quarters are those between the peak and trough of NBER business cycle. 

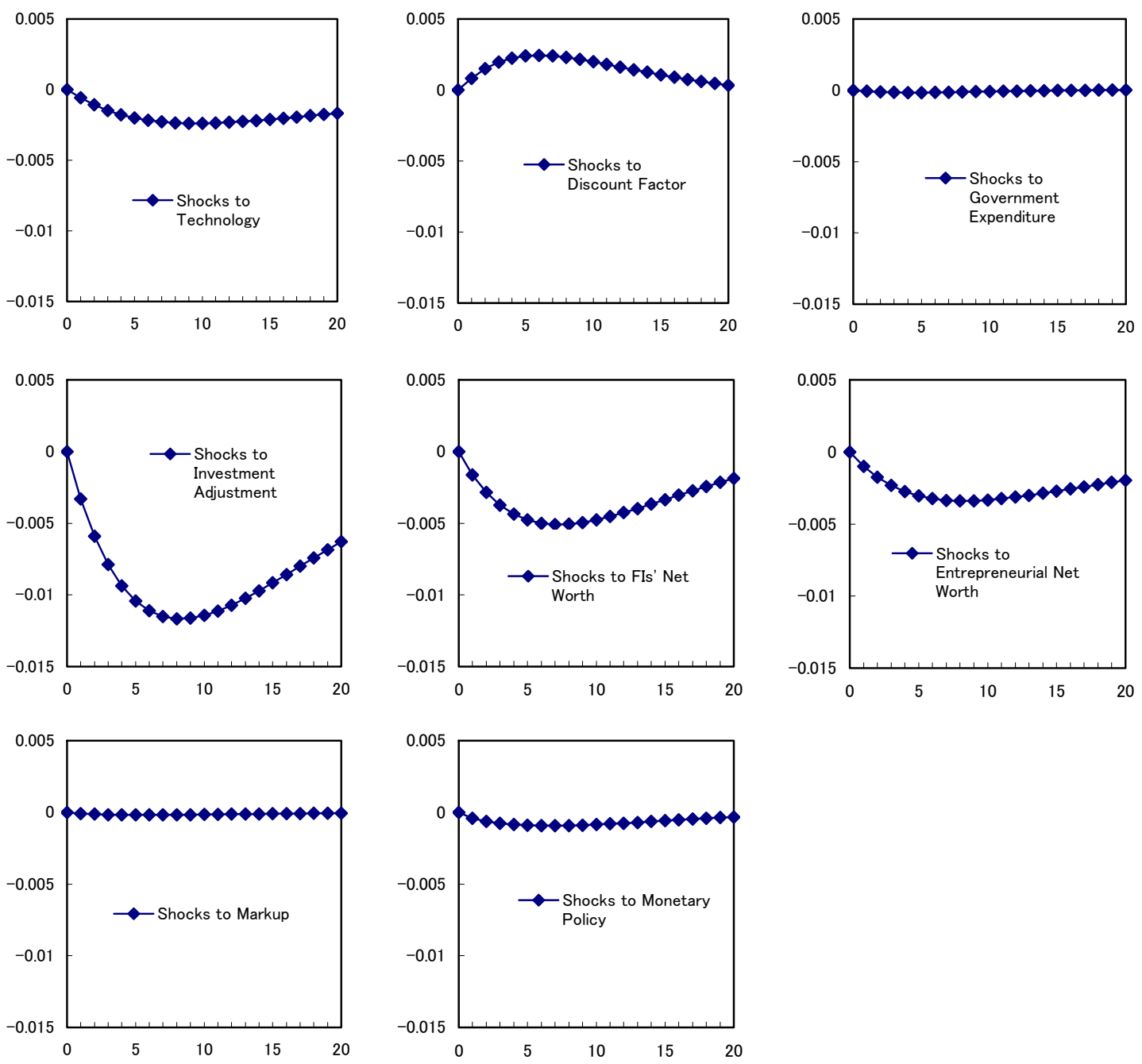

Figure 5: Impulse response of investment to each of the exogenous shock with the estimated size of one standard error. We give negative innovations to technology, FIs' net worth and entrepreneurial net worth, and positive innovations to all other shocks. 

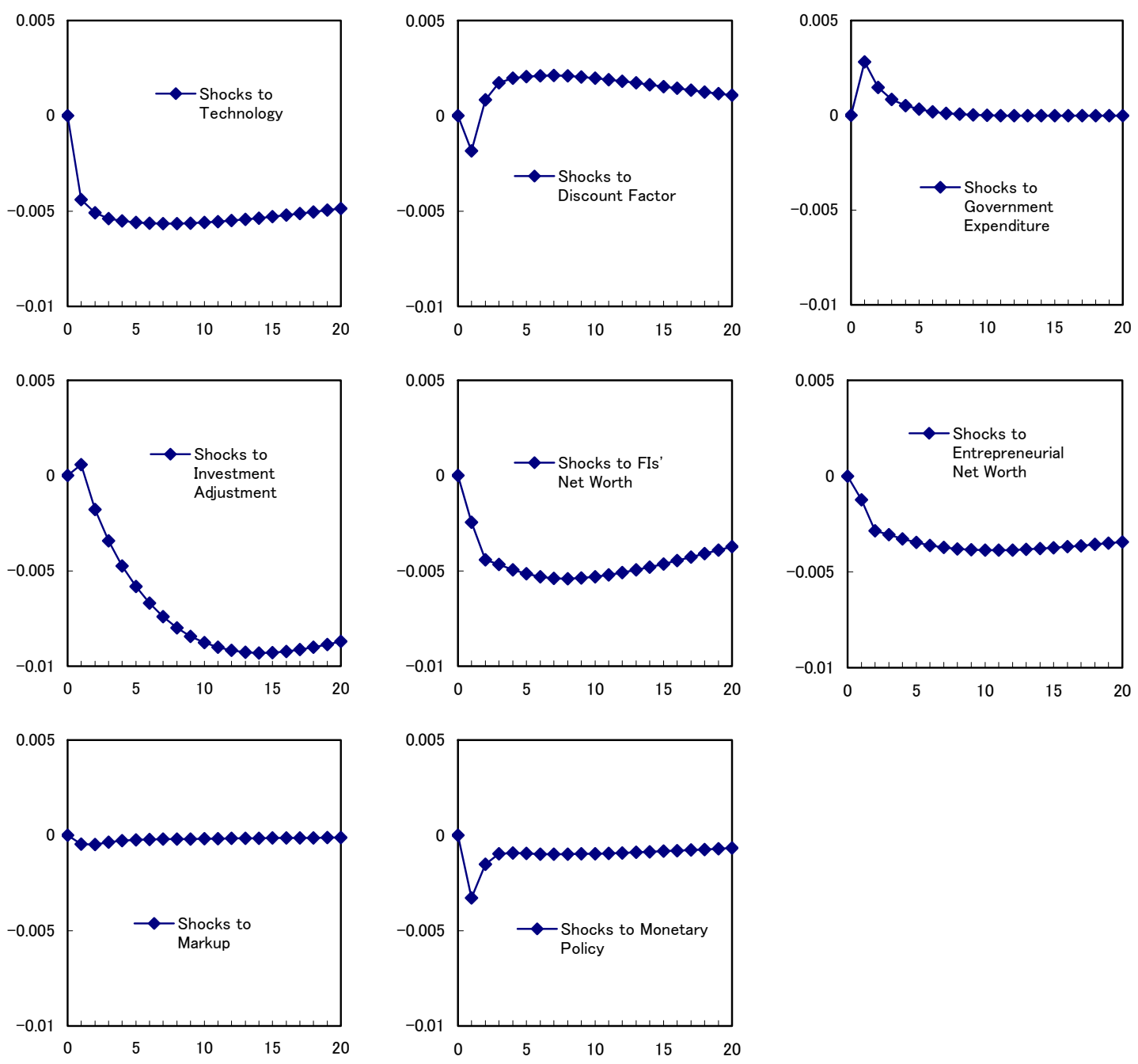

Figure 6: Impulse response of output to each of the exogenous shock with the estimated size of one standard error. We give negative innovations to technology, FIs' net worth and entrepreneurial net worth, and positive innovations to all other shocks. 

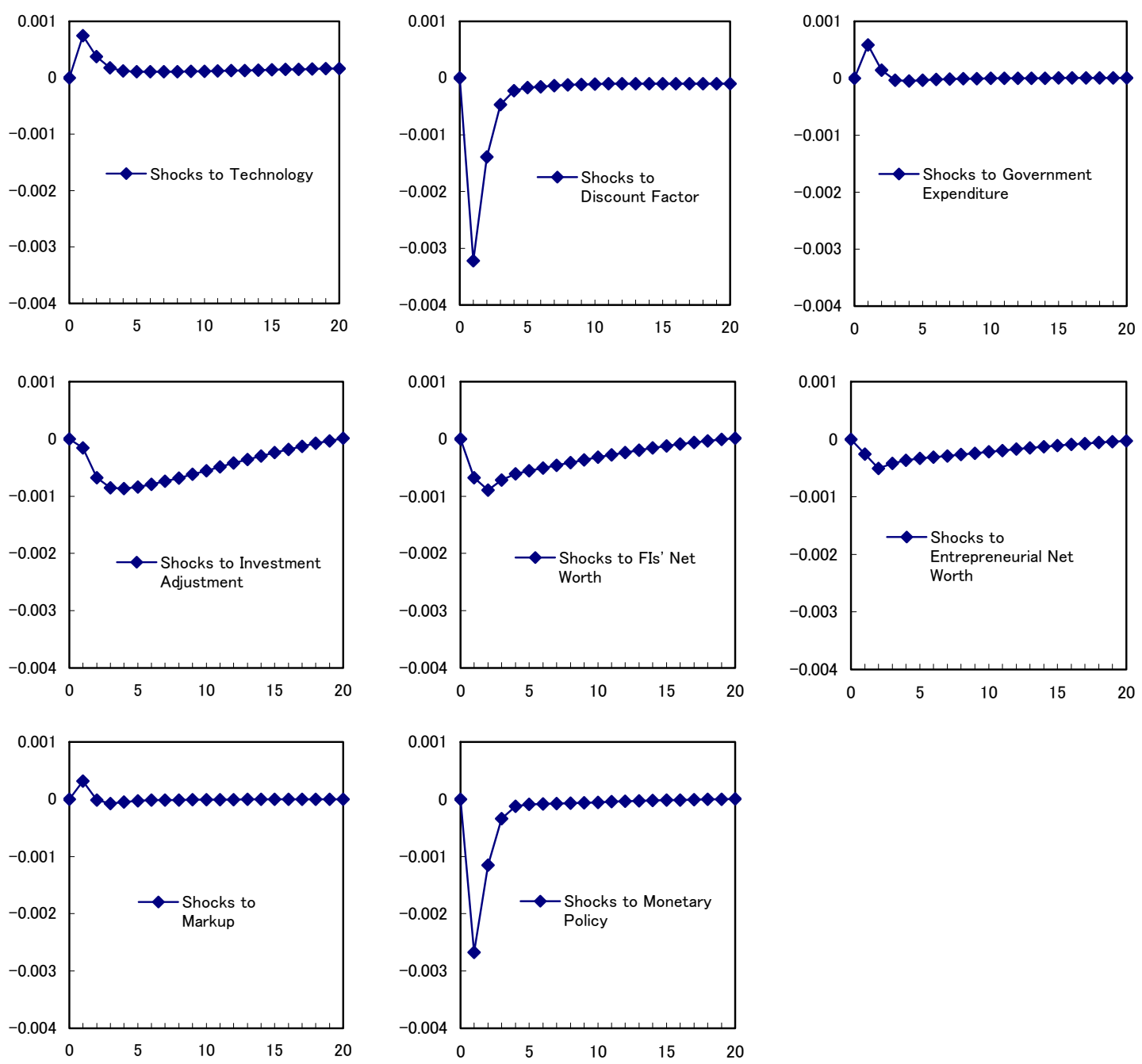

Figure 7: Impulse response of inflation to each of the exogenous shock with the estimated size of one standard error. We give negative innovations to technology, FIs' net worth and entrepreneurial net worth, and positive innovations to all other shocks. 


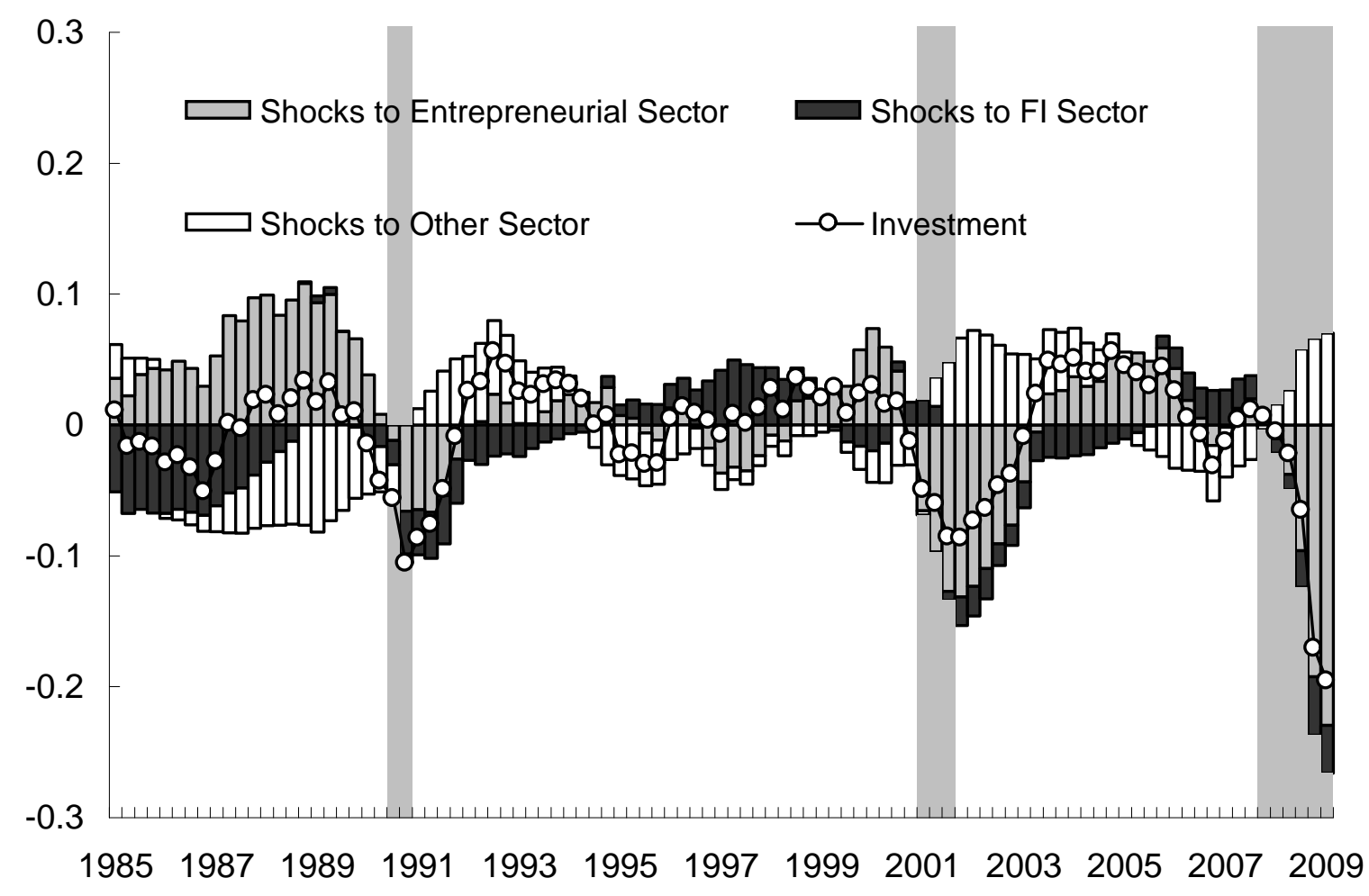

Figure 8: Historical decomposition of U.S. aggregate investment. (year-on-year \% change, deviation from trend growth) Shaded periods are those between the peak and trough of NBER business cycle. 


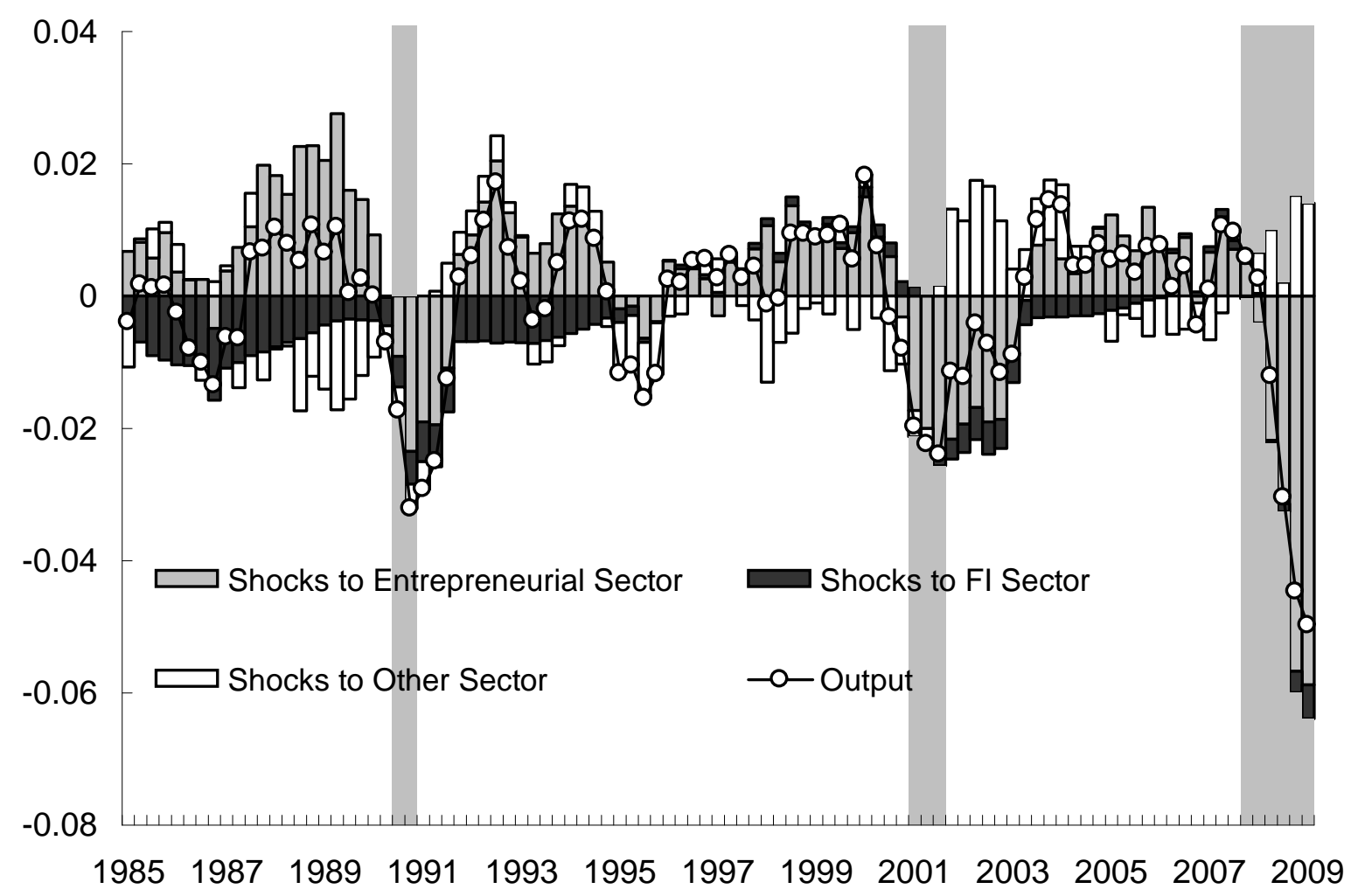

Figure 9: Historical decomposition of U.S. aggregate output. (year-on-year \% change, deviation from trend growth) Shaded periods are those between the peak and trough of NBER business cycle. 


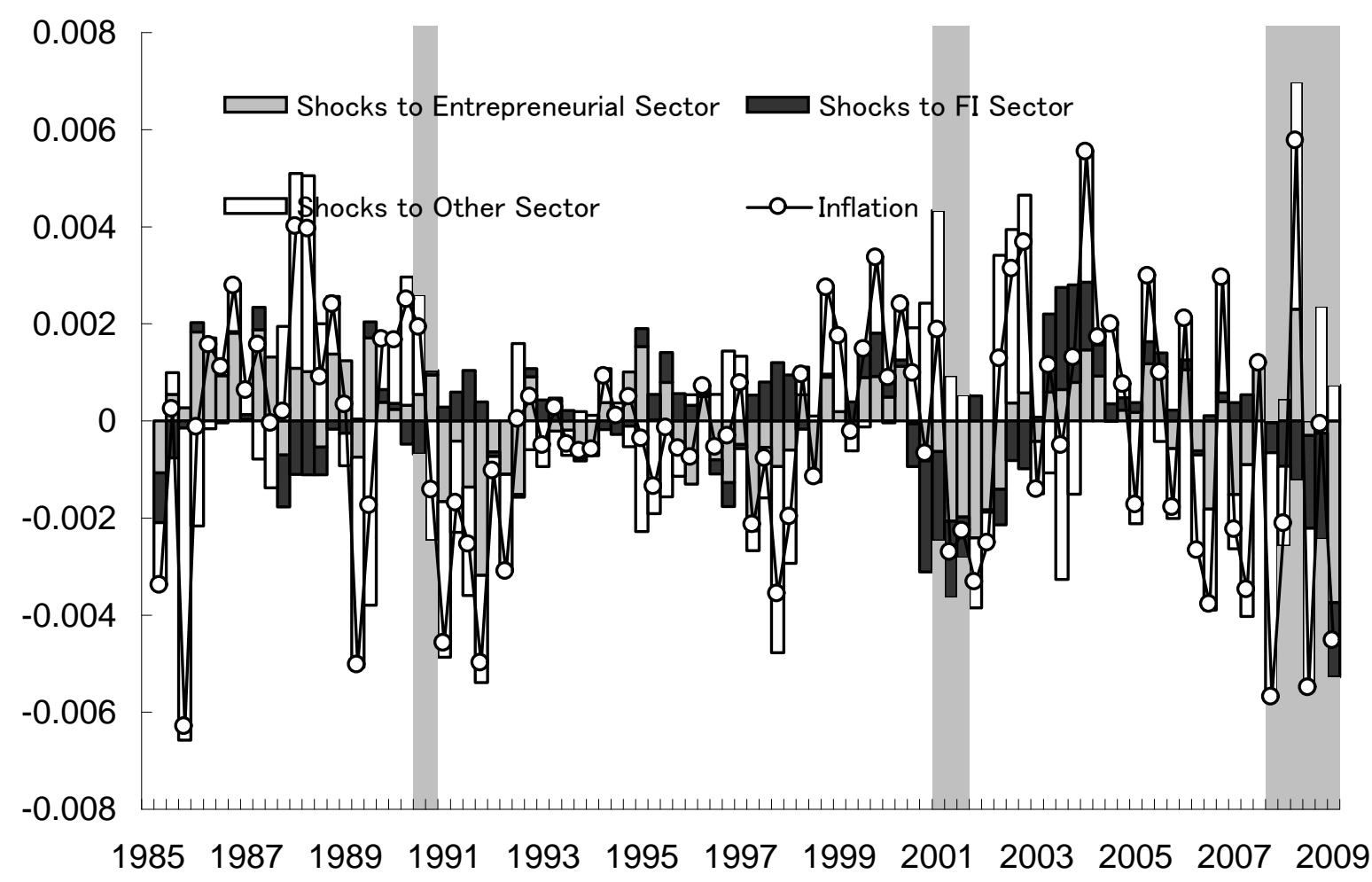

Figure 10: Historical decomposition of U.S. annual inflation. (quarterly difference of year-on-year \% change, deviation from mean) Shaded periods are those between the peak and trough of NBER business cycle. 
Table 1A: Parameters ${ }^{18}$

\begin{tabular}{ccc}
\hline Parameter & Value & Description \\
\hline$\beta$ & .99 & Discount factor \\
$\delta$ & .025 & Depreciation Rate \\
$\alpha$ & .35 & Capital Share \\
$R$ & $.99^{-1}$ & Risk Free Rate \\
$\epsilon$ & 6 & Degree of Substitutability \\
$\eta$ & 3 & Elasticity of Labor \\
$\chi$ & .3 & Utility weight on Leisure
\end{tabular}

\footnotetext{
${ }^{18}$ Figures are quarterly unless otherwise noted.
} 
This appendix provides parameterization of the variables that are related to the credit contracts among investors, FIs and entrepreneurs. The values are all taken from HSU. In HSU, we choose them so that they are consistent with the equilibrium conditions and the observed U.S. data.

Table 1B: Calibrated Parameters ${ }^{19}$

\begin{tabular}{ccc}
\hline Parameter & Value & Description \\
$\sigma_{F}$ & 0.107366 & S.E. of FIs Idiosyncratic Productivity at Steady State \\
$\sigma_{E}$ & 0.312687 & S.E. of Entrepreneurial Idiosyncratic Productivity at Steady State \\
$\mu_{F}$ & 0.033046 & Bankruptcy Cost associated with FIs \\
$\mu_{E}$ & 0.013123 & Bankruptcy Cost associated with entrepreneurs \\
$\gamma_{F}$ & 0.963286 & Survival Rate of FIs \\
$\gamma_{E}$ & 0.983840 & Survival Rate of Entrepreneurs
\end{tabular}

Table 1C: Steady State Conditions

$\begin{array}{cc}\text { Condition } & \text { Description } \\ R=.99^{-1} & \text { Risk-free rate is the inverse of the subjective discount factor. } \\ Z^{E}=Z^{F}+.023^{25} & \text { Premium for FIs' lending rate is } .023^{25} . \\ Z^{F}=R+.006^{25} & \text { Premium for FIs' borrowing rate is } .006^{25} . \\ F\left(\bar{\omega}^{F}\right)=.02 & \text { Default probability in the IF contract is } .02 . \\ F\left(\bar{\omega}^{E}\right)=.02 & \text { Default probability in the FE contract is } .02 . \\ n^{F}=.1 & \text { FIs' net worth/capital ratio is set to } .1 \\ n^{E}=.5 & \text { Entrepreneurial net worth/capital ratio is set to } .5 .\end{array}$

\footnotetext{
${ }^{19}$ Figures are quarterly unless otherwise noted.
} 
Table 2: Paramter Estimates

\begin{tabular}{c|crr|rrr}
\hline & \multicolumn{3}{|c}{ Prior distribution } & \multicolumn{3}{c}{ Posterior distribution } \\
& Distr. & Mean & St. Dev. & Mean & $5 \%$ & $95 \%$ \\
\hline$\xi_{p}$ & Beta & 0.5 & 0.15 & 0.578 & 0.472 & 0.695 \\
$\kappa$ & Normal & 4 & 1.5 & 6.928 & 5.107 & 8.605 \\
$\gamma_{p}$ & Beta & 0.5 & 0.2 & 0.202 & 0.017 & 0.354 \\
$\theta$ & Beta & 0.75 & 0.1 & 0.737 & 0.691 & 0.783 \\
$\phi_{\pi}$ & Normal & 1.5 & 0.125 & 1.555 & 1.389 & 1.716 \\
$\phi_{y}$ & Normal & 0.125 & 0.05 & 0.012 & -0.012 & 0.039 \\
$\rho_{B}$ & Beta & 0.5 & 0.2 & 0.857 & 0.821 & 0.898 \\
$\rho_{I}$ & Beta & 0.5 & 0.2 & 0.936 & 0.914 & 0.957 \\
$\rho_{A}$ & Beta & 0.5 & 0.2 & 0.973 & 0.953 & 0.992 \\
$\rho_{G}$ & Beta & 0.5 & 0.2 & 0.658 & 0.533 & 0.790 \\
$\rho_{R}$ & Beta & 0.5 & 0.2 & 0.155 & 0.059 & 0.245 \\
$\rho_{P}$ & Beta & 0.5 & 0.2 & 0.461 & 0.139 & 0.800 \\
\hline$\sigma\left(\epsilon_{B}\right)$ & Inv. Gamma & 0.01 & 2 & 0.0023 & 0.0017 & 0.0029 \\
$\sigma\left(\epsilon_{I}\right)$ & Inv. Gamma & 0.01 & 2 & 0.0065 & 0.0053 & 0.0077 \\
$\sigma\left(\epsilon_{G}\right)$ & Inv. Gamma & 0.01 & 2 & 0.0036 & 0.0032 & 0.0040 \\
$\sigma\left(\epsilon_{A}\right)$ & Inv. Gamma & 0.01 & 2 & 0.0057 & 0.0047 & 0.0068 \\
$\sigma\left(\epsilon_{R}\right)$ & Inv. Gamma & 0.01 & 2 & 0.0019 & 0.0016 & 0.0021 \\
$\sigma\left(\epsilon_{N_{F}}\right)$ & Inv. Gamma & 0.01 & 2 & 0.0771 & 0.0673 & 0.0869 \\
$\sigma\left(\epsilon_{N_{E}}\right)$ & Inv. Gamma & 0.01 & 2 & 0.1276 & 0.1129 & 0.1413 \\
$\sigma\left(\epsilon_{P}\right)$ & Inv. Gamma & 0.01 & 2 & 0.0112 & 0.0023 & 0.0176 \\
\hline
\end{tabular}

$L L=2473.5$ 
Table 3: Variance Decompositions

\begin{tabular}{|cc|ccc|}
\hline Category & & $\operatorname{var}\left(I_{t}\right)$ & $\operatorname{var}\left(G D P_{t}\right)$ & $\operatorname{var}\left(\pi_{t}\right)$ \\
& & & & \\
\hline \multirow{2}{*}{ Shocks to } & $\varepsilon_{t}^{A}$ & 2.64 & 7.74 & 4.82 \\
& & $(5.80)$ & $(10.25)$ & $(3.59)$ \\
Entrepreneurial & $\varepsilon_{t}^{I}$ & 68.10 & 74.48 & 21.02 \\
& & $(21.35)$ & $(63.52)$ & $(19.60)$ \\
Sector & $\varepsilon_{t}^{N_{E}}$ & 8.21 & 5.56 & 2.15 \\
& & $(10.68)$ & $(8.35)$ & $(2.64)$ \\
& \multirow{2}{*}{ sum } & 78.95 & 87.77 & 27.99 \\
& & $(37.83)$ & $(82.12)$ & $(25.84)$ \\
\hline \multirow{2}{*}{ Shocks to FI Sector } & $\varepsilon_{t}^{N_{F}}$ & 12.80 & 10.17 & 4.50 \\
& & $(20.49)$ & $(8.05)$ & $(5.10)$ \\
& & & \\
\hline \multirow{2}{*}{ Other Shocks } & \multirow{2}{*}{$\varepsilon_{t}^{b}$} & 5.05 & 0.94 & 31.84 \\
& & $(24.07)$ & $(4.72)$ & $(32.56)$ \\
& $\varepsilon_{t}^{g}$ & 0.01 & 0.25 & 0.89 \\
& & $(0.07)$ & $(1.18)$ & $(0.98)$ \\
& $\varepsilon_{t}^{p}$ & 0.00 & 0.00 & 0.00 \\
& & $(0.00)$ & $(0.00)$ & $(0.00)$ \\
& $\varepsilon_{t}^{r}$ & 3.18 & 0.87 & 34.79 \\
& & $(17.53)$ & $(3.94)$ & $(35.51)$ \\
& \multirow{2}{*}{ sum } & 8.23 & 2.06 & 67.52 \\
& & $(41.67)$ & $(9.83)$ & $(69.06)$ \\
\hline
\end{tabular}

Note: The estimated share of variance accounted by each shock is reported. Numbers are the average of 1984Q2 to 2009Q2. Those in parenthesis are the average of 1990Q1 to20091Q. 
Table 4: Estimates of Alternative Models

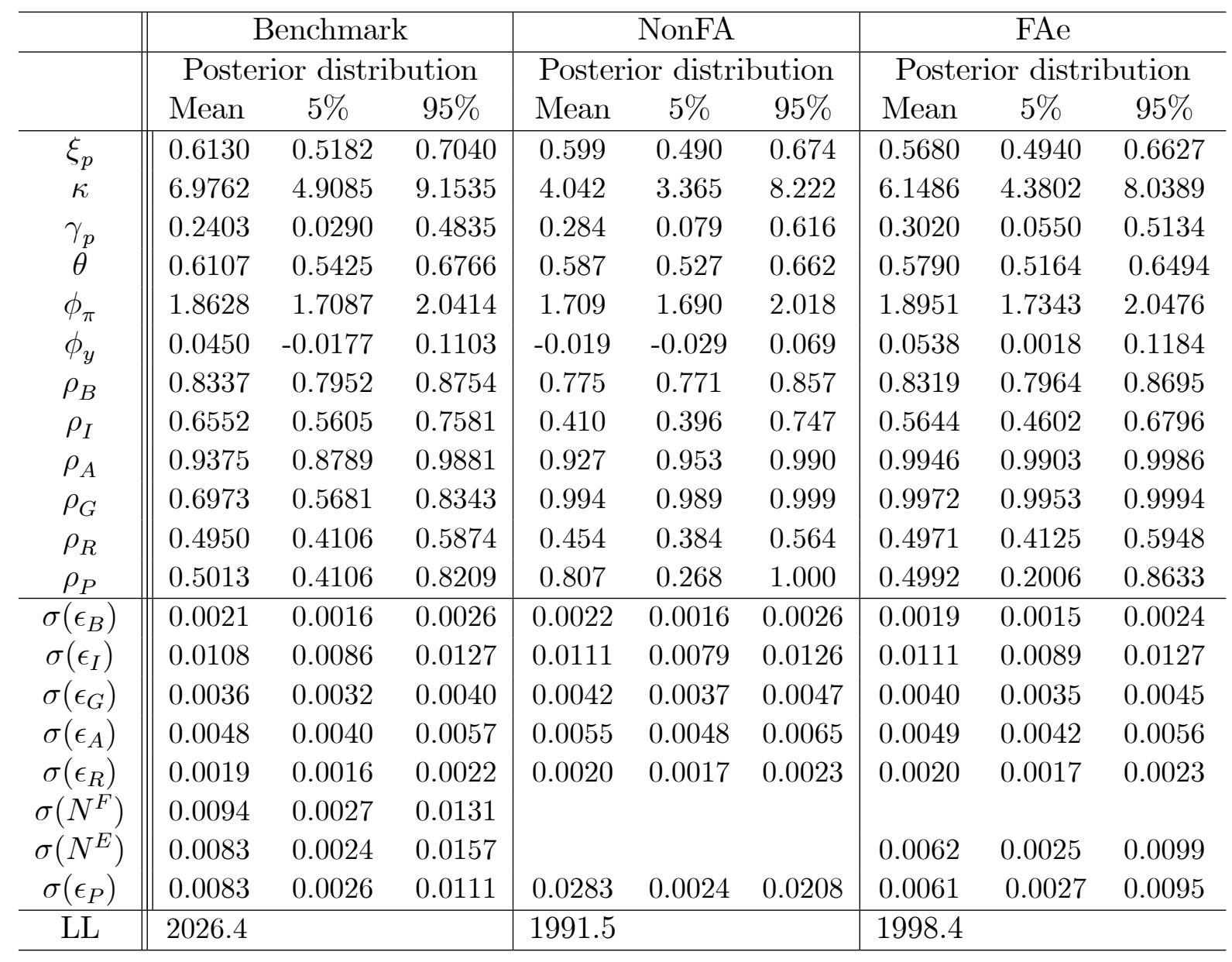


Table 5: Variance Decompositions of Investment

\begin{tabular}{|c|c|c|c|c|c|c|}
\hline \multicolumn{2}{|l|}{ Category } & \multirow{2}{*}{$\begin{array}{c}\text { II } \\
2.46 \\
(5.66)\end{array}$} & \multirow{2}{*}{$\begin{array}{c}\text { III } \\
6.20\end{array}$} & \multirow{2}{*}{$\begin{array}{c}\text { IV } \\
1.83 \\
(1.52)\end{array}$} & \multirow{2}{*}{$\begin{array}{c}\mathrm{V} \\
6.59 \\
(7.22)\end{array}$} & \multirow{2}{*}{$\begin{array}{c}\text { VI } \\
5.27 \\
(10.73)\end{array}$} \\
\hline Shocks to & $\varepsilon_{t}^{A}$ & & & & & \\
\hline Entrepreneurial & $\varepsilon_{t}^{I}$ & $\begin{array}{l}68.60 \\
(17.85)\end{array}$ & $\begin{array}{l}6.81 \\
(4.23)\end{array}$ & $\begin{array}{c}17.29 \\
(13.50)\end{array}$ & $\begin{array}{c}19.39 \\
(18.06)\end{array}$ & \\
\hline \multirow[t]{3}{*}{ Sector } & $\varepsilon_{t}^{N_{E}}$ & $\begin{array}{c}8.07 \\
(11.01)\end{array}$ & $\begin{array}{c}1.90 \\
(1.85)\end{array}$ & $\begin{array}{c}31.93 \\
(30.86)\end{array}$ & $\begin{array}{c}6.36 \\
(7.25)\end{array}$ & $\begin{array}{c}2.15 \\
(5.58)\end{array}$ \\
\hline & $\varepsilon_{t}^{\sigma_{E}}$ & $\begin{array}{c}0.00 \\
(0.00)\end{array}$ & $\begin{array}{c}1.89 \\
(1.71)\end{array}$ & & $\begin{array}{c}5.86 \\
(6.30)\end{array}$ & \\
\hline & sum & $\begin{array}{l}79.13 \\
(34.52)\end{array}$ & $\begin{array}{c}16.81 \\
(13.88)\end{array}$ & $\begin{array}{c}51.04 \\
(45.89)\end{array}$ & $\begin{array}{c}38.20 \\
(38.83)\end{array}$ & $\begin{array}{c}7.42 \\
(16.32)\end{array}$ \\
\hline Shocks to & $\varepsilon_{t}^{N_{F}}$ & $\begin{array}{c}12.74 \\
(22.20)\end{array}$ & $\begin{array}{l}58.69 \\
(55.69)\end{array}$ & $\begin{array}{c}14.15 \\
(12.83)\end{array}$ & $\begin{array}{l}4.68 \\
(4.37)\end{array}$ & $\begin{array}{c}8.21 \\
(16.24)\end{array}$ \\
\hline \multirow[t]{2}{*}{ FI Sector } & $\varepsilon_{t}^{\sigma_{F}}$ & $\begin{array}{c}0.00 \\
(0.00)\end{array}$ & $\begin{array}{c}12.22 \\
(11.83)\end{array}$ & & $\begin{array}{l}12.83 \\
(12.62)\end{array}$ & \\
\hline & sum & & $\begin{array}{l}70.91 \\
(75.80)\end{array}$ & & $\begin{array}{c}17.51 \\
(17.00)\end{array}$ & \\
\hline \multirow[t]{5}{*}{ Other Shocks } & $\varepsilon_{t}^{b}$ & $\begin{array}{c}4.67 \\
(23.55)\end{array}$ & $\begin{array}{l}3.22 \\
(2.45)\end{array}$ & $\begin{array}{c}14.73 \\
(12.34)\end{array}$ & $\begin{array}{c}11.84 \\
(11.89)\end{array}$ & $\begin{array}{r}10.76 \\
(4.19)\end{array}$ \\
\hline & $\varepsilon_{t}^{g}$ & $\begin{array}{c}0.01 \\
(0.07)\end{array}$ & $\begin{array}{c}0.00 \\
(0.00)\end{array}$ & $\begin{array}{c}0.02 \\
(0.02)\end{array}$ & $\begin{array}{c}0.00 \\
(0.00)\end{array}$ & $\begin{array}{c}0.04 \\
(0.10)\end{array}$ \\
\hline & $\varepsilon_{t}^{p}$ & $\begin{array}{c}0.00 \\
(0.00)\end{array}$ & $\begin{array}{c}0.00 \\
(0.00)\end{array}$ & $\begin{array}{c}0.71 \\
(0.62)\end{array}$ & $\begin{array}{c}0.00 \\
(0.00)\end{array}$ & $\begin{array}{c}63.13 \\
(32.29)\end{array}$ \\
\hline & $\varepsilon_{t}^{r}$ & $\begin{array}{c}3.45 \\
(19.66)\end{array}$ & $\begin{array}{c}9.03 \\
(7.84)\end{array}$ & $\begin{array}{c}19.33 \\
(17.35)\end{array}$ & $\begin{array}{c}32.39 \\
(32.25)\end{array}$ & $\begin{array}{c}10.44 \\
(30.86)\end{array}$ \\
\hline & sum & $\begin{array}{c}8.13 \\
(43.27)\end{array}$ & $\begin{array}{c}12.28 \\
(10.32)\end{array}$ & $\begin{array}{c}34.80 \\
(30.33)\end{array}$ & $\begin{array}{c}44.28 \\
(44.18)\end{array}$ & $\begin{array}{c}84.37 \\
(67.44)\end{array}$ \\
\hline
\end{tabular}

Note: The estimated share of variance accounted by each shock is reported. Numbers are the average of 1984Q2 to 2009Q2. Those in parenthesis are the average of 1990Q1 to2009Q2. 
Table 6: Variance Decompositions of Output

\begin{tabular}{|c|c|c|c|c|c|c|}
\hline \multicolumn{2}{|l|}{ Category } & \multirow{2}{*}{$\begin{array}{c}\text { II } \\
8.15 \\
(12.76)\end{array}$} & \multirow{2}{*}{$\begin{array}{c}\text { III } \\
72.07 \\
(71.26)\end{array}$} & \multirow{2}{*}{$\begin{array}{c}\text { IV } \\
15.80 \\
(12.93)\end{array}$} & \multirow{2}{*}{$\begin{array}{c}\mathrm{V} \\
59.00 \\
(61.13)\end{array}$} & \multirow{2}{*}{$\begin{array}{c}\text { VI } \\
5.71 \\
(11.53)\end{array}$} \\
\hline Shocks to & $\varepsilon_{t}^{A}$ & & & & & \\
\hline Entrepreneurial & $\varepsilon_{t}^{I}$ & $\begin{array}{l}73.95 \\
(59.51)\end{array}$ & $\begin{array}{c}2.71 \\
(2.51)\end{array}$ & $\begin{array}{l}4.24 \\
(3.56)\end{array}$ & $\begin{array}{c}2.24 \\
(2.07)\end{array}$ & \\
\hline \multirow[t]{3}{*}{ Sector } & $\varepsilon_{t}^{N_{E}}$ & $\begin{array}{r}5.43 \\
(8.36)\end{array}$ & $\begin{array}{l}1.05 \\
(1.01)\end{array}$ & $\begin{array}{c}29.29 \\
(27.89)\end{array}$ & $\begin{array}{c}0.08 \\
(0.08)\end{array}$ & $\begin{array}{c}0.69 \\
(1.51)\end{array}$ \\
\hline & $\varepsilon_{t}^{\sigma_{E}}$ & $\begin{array}{c}0.00 \\
(0.00)\end{array}$ & $\begin{array}{c}1.03 \\
(1.01)\end{array}$ & & $\begin{array}{c}1.62 \\
(1.68)\end{array}$ & \\
\hline & sum & $\begin{array}{l}87.53 \\
(80.63)\end{array}$ & $\begin{array}{c}76.86 \\
(75.79)\end{array}$ & $\begin{array}{l}49.34 \\
(44.38)\end{array}$ & $\begin{array}{c}63.62 \\
(65.66)\end{array}$ & $\begin{array}{l}6.39 \\
(13.04)\end{array}$ \\
\hline Shocks to & $\varepsilon_{t}^{N_{F}}$ & $\begin{array}{r}10.42 \\
(8.93)\end{array}$ & $\begin{array}{c}11.50 \\
(10.93)\end{array}$ & $\begin{array}{c}8.89 \\
(8.48)\end{array}$ & $\begin{array}{c}1.54 \\
(1.39)\end{array}$ & $\begin{array}{c}2.93 \\
(5.76)\end{array}$ \\
\hline FI Sector & $\varepsilon_{t}^{\sigma_{F}}$ & $\begin{array}{c}0.00 \\
(0.00)\end{array}$ & $\begin{array}{c}5.24 \\
(5.12) \\
16.74 \\
(19.32) \\
\end{array}$ & & $\begin{array}{c}13.61 \\
(14.35) \\
15.15 \\
(15.75)\end{array}$ & \\
\hline \multirow[t]{5}{*}{ Other Shocks } & $\varepsilon_{t}^{b}$ & $\begin{array}{c}0.92 \\
(4.90)\end{array}$ & $\begin{array}{c}4.63 \\
(3.48)\end{array}$ & $\begin{array}{l}35.17 \\
(28.70)\end{array}$ & $\begin{array}{c}15.71 \\
(13.95)\end{array}$ & $\begin{array}{c}8.98 \\
(8.62)\end{array}$ \\
\hline & $\varepsilon_{t}^{g}$ & $\begin{array}{c}0.26 \\
(1.26)\end{array}$ & $\begin{array}{c}0.10 \\
(0.08)\end{array}$ & $\begin{array}{c}0.50 \\
(0.41)\end{array}$ & $\begin{array}{c}0.03 \\
(0.03)\end{array}$ & $\begin{array}{c}0.17 \\
(0.40)\end{array}$ \\
\hline & $\varepsilon_{t}^{p}$ & $\begin{array}{c}0.00 \\
(0.00)\end{array}$ & $\begin{array}{c}0.06 \\
(0.04)\end{array}$ & $\begin{array}{c}0.67 \\
(0.45)\end{array}$ & $\begin{array}{c}0.00 \\
(0.00)\end{array}$ & $\begin{array}{c}76.58 \\
(60.60)\end{array}$ \\
\hline & $\varepsilon_{t}^{r}$ & $\begin{array}{c}0.88 \\
(4.27)\end{array}$ & $\begin{array}{c}1.61 \\
(1.28)\end{array}$ & $\begin{array}{c}5.44 \\
(4.24)\end{array}$ & $\begin{array}{c}5.11 \\
(4.31)\end{array}$ & $\begin{array}{c}4.95 \\
(11.58)\end{array}$ \\
\hline & sum & $\begin{array}{c}2.06 \\
(10.43)\end{array}$ & $\begin{array}{c}6.40 \\
(4.89)\end{array}$ & $\begin{array}{c}41.77 \\
(33.80)\end{array}$ & $\begin{array}{c}21.23 \\
(18.60)\end{array}$ & $\begin{array}{c}90.68 \\
(81.20)\end{array}$ \\
\hline
\end{tabular}

Note: The estimated share of variance accounted by each shock is reported. Numbers are the average of 1984Q2 to 2009Q2. Those in parenthesis are the average of 1990Q1 to2009Q2. 
Table 7: Variance Decompositions of Inflation

\begin{tabular}{|c|c|c|c|c|c|c|}
\hline Category & & II & III & IV & $\mathrm{V}$ & VI \\
\hline \multirow[b]{2}{*}{ Entrepreneurial } & $\varepsilon_{t}^{A}$ & $\begin{array}{c}4.96 \\
(3.69)\end{array}$ & $\begin{array}{c}9.44 \\
(9.31)\end{array}$ & $\begin{array}{c}4.95 \\
(4.10)\end{array}$ & $\begin{array}{c}1.76 \\
(1.89)\end{array}$ & $\begin{array}{c}11.82 \\
(16.81)\end{array}$ \\
\hline & $\varepsilon_{t}^{I}$ & $\begin{array}{l}21.94 \\
(20.12)\end{array}$ & $\begin{array}{c}2.68 \\
(2.05)\end{array}$ & $\begin{array}{c}0.96 \\
(0.77)\end{array}$ & $\begin{array}{c}1.55 \\
(1.43)\end{array}$ & \\
\hline \multirow[t]{3}{*}{ Sector } & $\varepsilon_{t}^{N_{E}}$ & $\begin{array}{c}2.13 \\
(2.62)\end{array}$ & $\begin{array}{c}0.86 \\
(0.82)\end{array}$ & $\begin{array}{c}2.04 \\
(1.97)\end{array}$ & $\begin{array}{c}0.15 \\
(0.17)\end{array}$ & $\begin{array}{c}2.33 \\
(3.92)\end{array}$ \\
\hline & $\varepsilon_{t}^{\sigma_{E}}$ & $\begin{array}{c}0.00 \\
(0.00)\end{array}$ & $\begin{array}{c}0.40 \\
(0.35)\end{array}$ & & $\begin{array}{c}0.28 \\
(0.29)\end{array}$ & \\
\hline & sum & $\begin{array}{l}29.03 \\
(26.43)\end{array}$ & $\begin{array}{c}13.37 \\
(12.54)\end{array}$ & $\begin{array}{c}7.96 \\
(6.85)\end{array}$ & $\begin{array}{c}3.74 \\
(3.78)\end{array}$ & $\begin{array}{c}14.15 \\
(20.73)\end{array}$ \\
\hline Shocks to & $\varepsilon_{t}^{N_{F}}$ & $\begin{array}{c}4.40 \\
(5.03)\end{array}$ & $\begin{array}{l}10.54 \\
(9.25)\end{array}$ & $\begin{array}{c}0.86 \\
(0.81)\end{array}$ & $\begin{array}{c}0.41 \\
(0.37)\end{array}$ & $\begin{array}{c}8.26 \\
(10.83)\end{array}$ \\
\hline \multirow[t]{2}{*}{ FI Sector } & $\varepsilon_{t}^{\sigma_{F}}$ & $\begin{array}{c}0.00 \\
(0.00)\end{array}$ & $\begin{array}{c}2.90 \\
(2.75)\end{array}$ & & $\begin{array}{c}0.60 \\
(0.60)\end{array}$ & \\
\hline & sum & & $\begin{array}{c}13.43 \\
(32.01)\end{array}$ & & $\begin{array}{c}1.01 \\
(0.97)\end{array}$ & \\
\hline \multirow[t]{5}{*}{ Other Shocks } & $\varepsilon_{t}^{b}$ & $\begin{array}{c}31.76 \\
(32.68)\end{array}$ & $\begin{array}{c}25.39 \\
(16.80)\end{array}$ & $\begin{array}{c}48.82 \\
(36.14)\end{array}$ & $\begin{array}{c}64.53 \\
(67.65)\end{array}$ & $\begin{array}{c}0.41 \\
(0.58)\end{array}$ \\
\hline & $\varepsilon_{t}^{g}$ & $\begin{array}{c}0.86 \\
(0.95)\end{array}$ & $\begin{array}{c}0.36 \\
(0.29)\end{array}$ & $\begin{array}{c}0.22 \\
(0.17)\end{array}$ & $\begin{array}{c}0.24 \\
(0.21)\end{array}$ & $\begin{array}{c}0.13 \\
(0.23)\end{array}$ \\
\hline & $\varepsilon_{t}^{p}$ & $\begin{array}{c}0.00 \\
(0.00)\end{array}$ & $\begin{array}{c}4.60 \\
(3.38)\end{array}$ & $\begin{array}{c}8.07 \\
(5.36)\end{array}$ & $\begin{array}{c}2.00 \\
(1.53)\end{array}$ & $\begin{array}{c}58.28 \\
(32.41)\end{array}$ \\
\hline & $\varepsilon_{t}^{r}$ & $\begin{array}{c}33.96 \\
(34.91)\end{array}$ & $\begin{array}{c}42.84 \\
(34.97)\end{array}$ & $\begin{array}{c}34.08 \\
(28.65)\end{array}$ & $\begin{array}{c}28.47 \\
(25.86)\end{array}$ & $\begin{array}{c}18.77 \\
(35.22)\end{array}$ \\
\hline & sum & $\begin{array}{c}66.57 \\
(68.54)\end{array}$ & $\begin{array}{c}73.19 \\
(55.44)\end{array}$ & $\begin{array}{c}91.19 \\
(70.32)\end{array}$ & $\begin{array}{l}95.24 \\
(95.25)\end{array}$ & $\begin{array}{c}77.59 \\
(68.44)\end{array}$ \\
\hline
\end{tabular}

Note: The estimated share of variance accounted by each shock is reported. Numbers are the average of 1984Q2 to 2009Q2. Those in parenthesis are the average of 1990Q1 to2009Q2. 